\title{
The Effect of Relative Humidity and Surface Wind Speed on the Volumetric Water Content of the Soil for Selected Stations in Iraq
}

\author{
[Dr. Osama Tarek Al-Taai and Thaer Kadum Jawad]
}

\begin{abstract}
Soil Water content plays an important role in global hydrological cycles and regional climate of development weather patterns, plus its take part on production of precipitation and climate change. The aim of this work is to determine the effect of some of meteorological elements on the volumetric soil water content at the first level of the soil $(0.0$ 0.07 meter) and study volumetric soil water content for four levels of the soil, and the extent of the volumetric soil water content change at the first level, including with time for four selected areas of Iraq Baghdad, Basra, Mosul and Rutba and four months January, March, July and September during the 33year period from 1979 to 2011. Work was performed with monthly data relative humidity, surface wind speed at a height of 10 meters and the volumetric soil water content for four levels of the soil. And taken from the European Center (ECMWF), specifically model (ERA- Interim), by taking advantage of some statistical techniques such as simple linear regression, the correlation coefficients Mann-Kendall and spearman rho. The results showed that the volumetric soil water content at the first level of the soil in the event of an increase in all study areas for months January, July and September, and this is shown by the results of the tests and the values of slope, has recorded the greatest value of the correlation coefficient of 0.3 and 0.4 in Baghdad in September and Basra in the month of July and both tests in a row except the connector is in the case of a decrease in the month of January, while in the month of March in the case of a decrease for all study areas have recorded the greatest value for the correlation coefficient of $\mathbf{- 0 . 3}$ and $\mathbf{- 0 . 5}$ in Mosul, and both tests in a row and showed the tests the existence of a few counterproductive correlations to the medium in the month of March for all study areas, the relationship between relative humidity and volumetric soil water content they are a direct correlation medium to high when months January and March, there is no linear relationship in the months July and September for all study areas, recorded the greatest value of the correlation coefficient of 0.6 and 0.7 in the Rutba in the month of January, but both tests, respectively. The surface wind speed relationship of volumetric soil water content is an inverse relationship a few to medium when months January and March in Baghdad and Basra, and there is no linear relationship in the months July and September,
\end{abstract} Dr. Osama Tarek Al-Taai
1: Dep. of Atmospheric Sciences /College of Science /Al-Mustansiriyah Univ.
2: Baghdad / IRAQ

Thaer Kadum Jawad

1: Dep. of Atmospheric Sciences /College of Science/Al-Mustansiriyah Univ. 2: Baghdad / IRAQ
Has recorded the greatest value of the correlation coefficient -0.3 and -0.4 in Basra in the month of January, but both tests, respectively. The Mosul and Rutba, influenced by a direct effect surface wind speed, as the volumetric soil water content decreases increasing surface wind speed and vice versa, and this is evident in the month of January in the Rutba becomes the relationship is a positive medium, and there is no linear relationship between volumetric soil water content and surface wind speed in the months March, July and September and this is evident from the high values of $P$-value.

Keywords- Soil water, Relative humidity, Wind speed, Spearman rho test, Iraq.

\section{Introduction}

The water content of the soil variable head on a large scale in many environmental studies, including meteorology, hydrology, agriculture and climate change. The effect on the soil surface, especially at a depth of one to two meters, which is the key to the interaction between the Earth and the atmosphere, and is one of the key variables that control the water and thermal energy exchange between the Earth's surface and atmosphere by evaporation and plant transpiration. This variable has multiple links with other meteorological variables, making it effective in from the predictive significantly [1]. Despite being a very small layer compared with the global total amount of water but they are very important in many of the basic operations of many hydrologists and chemistry and biology, an important variable is used in many applications such as numerical weather forecasts and monitoring of global climate change and forecasting in runoff modeling and evaporation, so it's important to careful monitoring and assessment of spatial and temporal variations of the water content of the soil [2]. Agriculture is the most influential sector economically weather, severe such as drought and based many other economic sectors in the community to agro-ecosystems, which is a specific form of air-conditioned ecosystem of humans for food production [3]. So the drought can have a lot of economic and social impacts negative, such as loss of income in the agriculture and food industries, and the high costs of large water production techniques such as irrigation systems [4].

\section{Soil Water Content}

Soil is considered an object porous contain a percentage of the spaces between the particles, these pores are busy with water that reaches the soil in multiple ways irrigation, 
rain and other methods is called in this case soil water, and soil water is necessary because it is absorbed mediated developing plant roots through the stages of growth different [5] and no soil water in equilibrium with soil air is also located within the pores of the soil and soil air is also necessary to breathe developing plant roots, as shown in "Fig. 1" and knows the soil water content that the amount of moisture or water inside the pores of the soil and on the surface of soil particles attributed to completely dry soil mass [6].

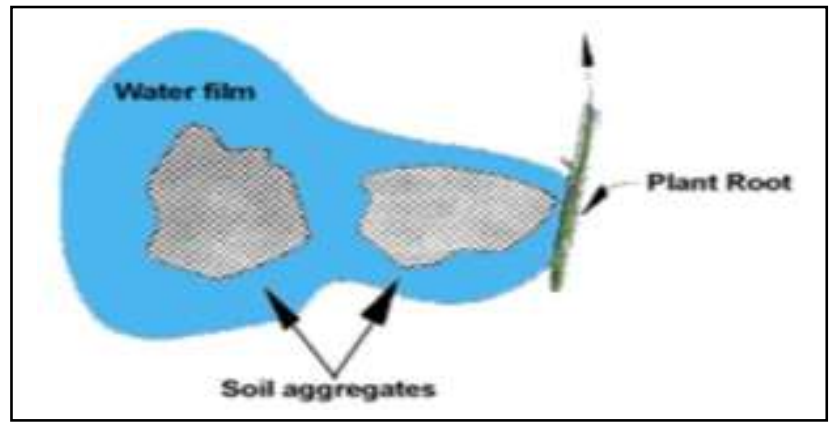

Figure 1. The presence of water between soil particles [6].

The surface soil moisture are available water at a depth of $10 \mathrm{~cm}$ of soil, while soil moisture root zone is water available for plants, which are generally at a depth of $200 \mathrm{~cm}$ from the soil [7]. Soil and retain water in the form of moisture, which can plants absorbed for a long time and allows for the process of chemical weathering of soil mineralogy to continue as it happens changes in the mineral, chemical and physical properties which are known operations are soil (the evolution of the soil), as lead chemical weathering of soil mineralogy to the exit of some nutrients such as (Potassium (K), Sodium $(\mathrm{Na})$, Calcium (Ca), Manganese (Mn), Magnesium (Mg) and Iron $(\mathrm{Fe})$ ) [8], of various minerals crystals to the aqueous solution (soil solution) in the form of dissolved ions which makes it available to the plant as the percentage of moisture retained in the soil affect the other physical properties such as swelling and contraction, especially in clay soils containing a large proportion of metal Montmorillonite [9].

\section{Weather Elements}

Weather or climate both express air case means this case a composite air, any manifestation caused by the interaction between several elements, though which may popularized the expressions of the weather on the basis of a single element as they say (cold weather, dry, rainy...etc.) [10]. as soon as possible to the reality and significance. The air case any were the result of the interaction of many elements represented in the heat and humidity of air and atmospheric pressure, wind, and other meteorological elements, and of these elements are subject to the influence of a combination of factors which play a major role in shaping climate conditions that are caused by a combination of climatic elements interaction that climate change and the occurrence of fluctuations which has implications both near and far-term natural resources on the Earth's surface also has an impact on the (environment, agriculture, industry, construction and other activities), this increased the need to assess and address the data of meteorology to benefit from them in the future, especially for the area under study and in what comes clarify some meteorological elements to illustrate the behavior of each of them and related to each other [11] [12].

\section{A. Relative Humidity}

Is the water vapor in the air relative to what can air carry water vapor at the same temperature and atmospheric pressure himself, calculated as follows: [13]

$$
\text { Relative Humidity }=\frac{\text { actual water vapor pressure }}{\text { saturated water vapor pressure }} * 100 \%
$$

$$
\text { Relative Humidity }=\frac{\text { actual specific humidity }}{\text { saturated specific humidity }} * 100 \%
$$

Can determine the relative humidity of the mixture of air with water vapor using moisture schemes (psychometric charts) if we know the degree of the dry bulb temperature (T) and the degree of the wet bulb temperature (Tw) to mix these quantities easily estimated using the dry and wet thermometer and control of air relative humidity in the evaporation of water surfaces, soil and transpiration from the leaves of the plant rate, the greater the relative humidity is less evaporation and transpiration and vice versa because the saturated water vapor pressure depends on the temperature, so the relative humidity change during the day depending on to change the temperature relative humidity rises as during the hours of the night cold sometimes even up to the point of saturation, resulting in what is known as dew if the temperature is above zero percentile, and if they are produced without frost. In the middle of the day when the temperature reaches its peak, the relative humidity drops to its lowest rate increases the rate of evaporation and transpiration, at any temperature increase relative humidity decreases and vice versa. As the relative humidity increases decreasing the temperature to the sample up to saturation of any relative humidity equal to $100 \%$, this class is called degree dew which then condenses water vapor into water, and to illustrate this by the following relationship when $(\mathrm{RH}>50 \%)$ :

$$
\mathrm{RH}=100-5\left(\mathrm{~T}-\mathrm{T}_{\mathrm{d}}\right)
$$

Where ( $\mathrm{RH})$ is relative humidity, $(\mathrm{T})$ is temperature for dry air and $\left(\mathrm{T}_{\mathrm{d}}\right)$ is dew point temperature [14].

\section{B. Wind Speed}

Wind is the movement of air from high pressure areas to the low pressure areas, and established the high-pressure areas and the low variations in temperature caused by the heat of the Earth's surface, which in turn causes a rise in atmospheric temperatures sunlight [15]. The main source of wind energy is solar energy is estimated that $1 \%$ of the total incident solar radiation that reaches the surface of the value of the land is converted to wind power and for the following reasons [16]:

- Earth heating between the equator and the northern and southern poles variation. 
- Heating the earth and the seas and oceans contrast.

- Contrast heating valleys hills and mountains.

- Earth's rotation on its axis.

The horizontal variation in temperature tends to create a horizontal divergence and vertical at atmospheric pressure, is also linked to temperature and atmospheric pressure direct correlation, the direct relationship between temperature and atmospheric pressure are more things responsibility for causing the wind movement and dividend pressure in the atmosphere such as areas high pressure and the low, it can be by looking at the map which has isobar lines convergent which reflects the large horizontal change in pressure and distances horizontal short the other thing that contributes to the increase of wind speed is convection and raise the antenna of expulsion, which is warmed by the earth's surface often reflected cumulus clouds [17]. From the foregoing it is clear that the relationship of temperature quickly wind is a positive relationship as the wind increased activity when the temperature increases and vice versa when the temperature drops decreasing wind speed [18]. And reason for the formation of sandy soil or sand dunes or Ablation and liquidation rocky soil of fine sand first due to the wind that do not move just fine rock-grained but are rubbed together and crushed, and then when weaken the power deposition to form the so-called soil air because the air was his the greatest influence in the formation [19].

\section{Data and Study Area}

Work was performed with monthly data (volumetric soil water content for four level, relative humidity and surface wind speed at a height of 10 meters) taken from the European Center Medium Weather Forecasts (ECMWF) specifically model (ERA-Interim), the data has been converted to an integrated set monthly for the purpose of showing the effect of the monthly change [20][21]. Soil is divided into four levels, according to the divisions (ECMWF According to the project (TESSEL) Tiled ECMWF Scheme for Surface Exchange over Land first level, a surface layer of the soil and be at depth (0.0-0.07 meter) symbolized by the (SWVL1) The second level is also a layer close to the surface of the earth and be at a depth of (0.07-0.28 meter) symbolized by the (SWVL2) the third level shall be at a depth of (0.28-1.0 meter) has the symbol (SWVL3) the fourth level shall be at a depth of (1.02.89 meter) and has the symbol (SWVL4), and this data is measured volumetric units $\left(\mathrm{m}^{3} \mathrm{~m}^{-3}\right)$ so-called volumetric water content of the soil [22][23]. Was selected areas (Baghdad, Basra, Mosul and Rutba) of this accident (Central, South, North and West) Iraq respectively, as the soil of this region consists of four types of soils and specifications of the study areas as shown in the "Table 1" and "Fig. 2", and classified according to the FAO/UNESCO organization in 1962[24][25].

TABLE 1. Study areas and type of soil [24].

\begin{tabular}{|c|c|c|c|c|}
\hline Areas & $\begin{array}{c}\text { Altitude } \\
\text { (Meter) }\end{array}$ & $\begin{array}{c}\text { Latitude } \\
\text { (Degree North) }\end{array}$ & $\begin{array}{c}\text { Longitude } \\
\text { (Degree East) }\end{array}$ & $\begin{array}{c}\text { Soil } \\
\text { Type }\end{array}$ \\
\hline Baghdad & 32 & 33.233 & 44.233 & Loams \\
\hline
\end{tabular}

\begin{tabular}{|c|c|c|c|c|}
\hline Basra & 5 & 30.567 & 47.783 & Sand \\
\hline Mosul & 216 & 36.317 & 43.150 & $\begin{array}{c}\text { Reddish } \\
\text { Brown }\end{array}$ \\
\hline Rutba & 629 & 33.033 & 40.283 & Sand \\
\hline
\end{tabular}

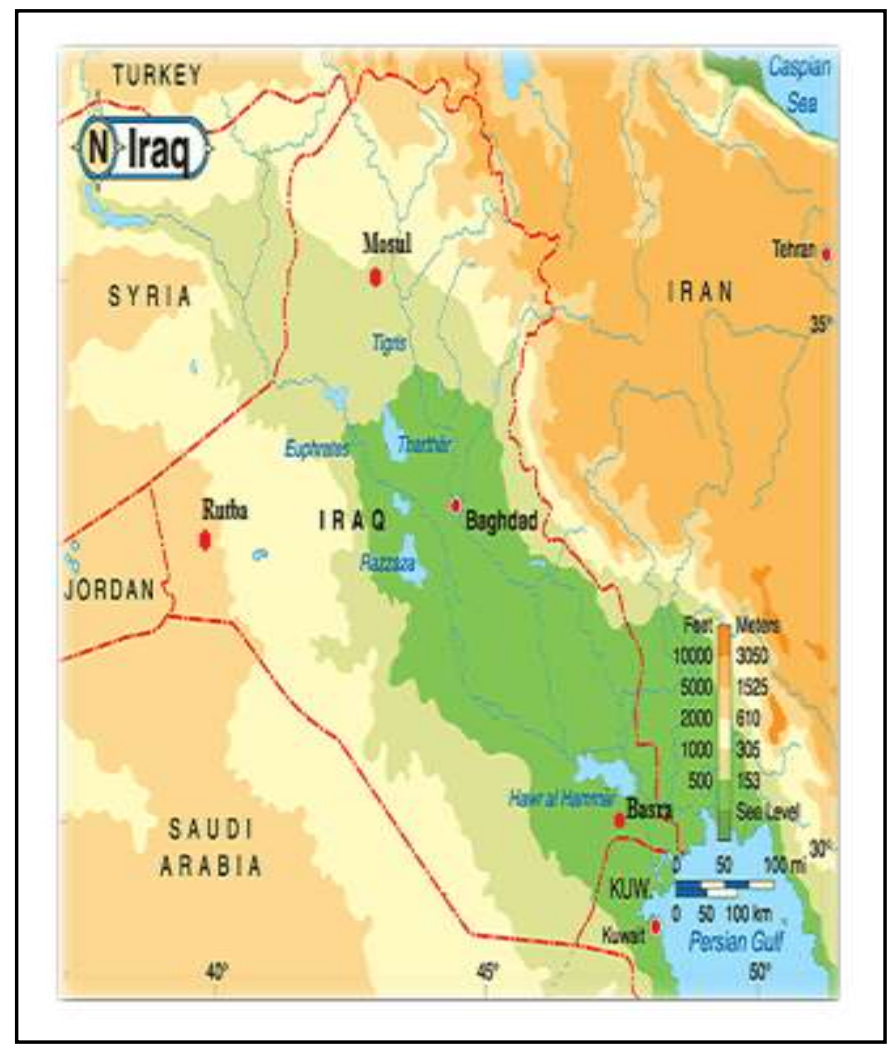

Figure 2. Soil type for each study area sites [26].

\section{v. Statistics Used}

Several statistical tests available were conducted were selected test Mann-Kendall and Spearman Rho test for the order of this work has been selected regression analysis and in particular the simple linear regression to predict the relationship between soil water content and meteorological parameter were used statistical program Statistical Package for the Social Sciences (SPSS) to calculate the tests on the water content and data elements meteorological program SigmaPlot to calculate the value of the slope of the regression and the value of $\mathrm{P}$-value simple linear regression way.

\section{A. Simple Linear Regression (SLR)}

Simple linear regression is the study of the relationship between two variables just to get to the linear relationship (i.e. a straight line equation) between these two variables, a parametric test, which assumes that the data are distributed normally distributed and to find out the gradient value is calculated slope of the regression through the linear equation of the following: [27]

$$
\overline{\mathrm{Y}}=\mathrm{a}+\mathrm{b} \overline{\mathrm{X}}
$$




$$
\mathrm{b}=\frac{\sum_{\mathrm{i}=1}^{\mathrm{n}}\left(\mathrm{X}_{\mathrm{i}}-\overline{\mathrm{X}}\right)-\left(\mathrm{Y}_{\mathrm{i}}-\overline{\mathrm{Y}}\right)}{\sum_{\mathrm{i}=1}^{\mathrm{n}}\left(\mathrm{X}_{\mathrm{i}}-\overline{\mathrm{X}}\right)^{2}}
$$

Where:

a: Steady decline or part of the lump axis $(\bar{Y})$ to the equation of the straight line (equation 4).

b: Slope of the regression and found a mile straight line.

\section{B. Probability Value (P-Value)}

Is purely a statistical term, a number is used to assess the statistical measures, which show that the value of the corresponding factor is actually an influential factor or not?

If the (P-Value) less than 0.05 , the corresponding factor is an influential factor in the variable that we are trying to study the change. Influential factor has even consider the value of (P-Value) is equal to 0.1 , but that increased about 0.1 , this factor should be excluded from the model is ineffective [28].

\section{Mann-Kendall Test}

A technique used test orientation and strength of the relationship between two variables in other words, is a tool to show whether any of the same group numbers has an impact on another set of numbers, has been used this test in the field of hydrology and climate random testing with the trend of the time series is based procedure on the basis of ranks, a strong influence of extremism and test well data deviation and can be expressed in the following equation Kendall- $\tau$ [29]:

$$
\begin{aligned}
& \tau=\frac{\sum_{i<j}(\operatorname{sgn}(x i-x j) \operatorname{sgn}(y i-y j))}{\sqrt{\left(T_{0}-T_{1}\right)\left(T_{0}-T_{2}\right)}} \\
& T_{0}=\frac{n(n-1)}{2} \\
& T_{1}=\frac{\sum_{k} t_{k}\left(t_{k}-1\right)}{2} \\
& T_{2}=\frac{\sum_{1} u_{1}\left(u_{1}-1\right)}{2}
\end{aligned}
$$

Where:

$t_{k}$ : is the value of the correlation to the values of $(x)$ in the range $(\mathrm{k})$.

$\mathrm{u}_{1}$ : is the correlation to the values of (y) value in the range (1).

$\mathrm{n}$ : is the number of observed values.

(xi-xj): observed data towards the ( $\mathrm{x}$-axis).

(yi-yj): observed data towards the (y-axis).

And know the value of $\operatorname{sgn}(\mathrm{z})$ the following equation:

$$
\operatorname{sgn}(z)=\left\{\begin{array}{c}
1 \text { if } z>0 \\
0 \text { if } z=0 \\
-1 \text { if } z<0
\end{array}\right.
$$

\section{Spearman Rho Test}

Is a test of non-parametric range of observed data $\left\{X_{i}, i=\right.$ $1,2, \ldots, \mathrm{n}\}$ based on nothingness any hypothesis that all $\left(\mathrm{X}_{\mathrm{i}}\right)$ values are independent and have the same distribution and to calculate the Spearman rho coefficient statistical ranks $\left(r_{s}\right)$ must be converted model original to the ranks mediated arranged in descending order in terms of amount is then calculate the amount of $\left(\mathrm{d}_{\mathrm{i}}\right)$ through $\left(\mathrm{d}_{\mathrm{i}}=\mathrm{k}_{\mathrm{i}}-\mathrm{i}\right)$ where (i) value ranging from 1 to $(n)$ and $\left(r_{s}\right)$ is given by the following: [30]

$$
\mathrm{r}_{\mathrm{s}}=1-\frac{6 \sum_{\mathrm{i}=1}^{\mathrm{n}} \mathrm{d}_{\mathrm{i}}^{2}}{\mathrm{n}\left(n^{2}-1\right)}
$$

If the great value (n) can test the value of $\left(r_{s}\right)$ importance by calculating the amount of $\left(\mathrm{t}_{\mathrm{s}}\right)$ which is given by equation:

$$
\mathrm{t}_{\mathrm{s}}=\mathrm{r}_{\mathrm{s}} \sqrt{\frac{\mathrm{n}-2}{1-\mathrm{r}_{\mathrm{s}}{ }^{2}}}
$$

If the value of $\left(t_{s}\right)$ false calculated within the trusted boundary for two-tailed test of this we can deduce that there is no trend in the data series. Through "Table 2", we can determine the value of the degree of correlation and interpretation of test transactions for both tests.

TABLE 2. The degree of correlation and interpretation of test transactions [31].

\begin{tabular}{|c|c|c|}
\hline Value & $\begin{array}{c}\text { Degree of } \\
\text { Correlation }\end{array}$ & $\begin{array}{c}\text { Interpretation of } \\
\text { Relationship }\end{array}$ \\
\hline Less than 0.2 & Slight & No relationship \\
\hline 0.2 to 0.4 & Few & Small \\
\hline 0.4 to 0.7 & Medium & Acceptable \\
\hline 0.7 to 0.9 & High & Special \\
\hline 0.9 or above & Very high & Strong \\
\hline
\end{tabular}

\section{Results and Discussion}

\section{A. Analysis of the General Behavior of the Volumetric Soil Water Content for Four Levels}

When analyzing the general behavior of the monthly average volumetric soil water content, described by "Fig. 3", found that the greatest value of the volumetric soil water content have been recorded in Mosul and the lowest value has been registered in Basra, and can be seen that there is a large variation in the amount of volumetric soil water content when the first and second levels of all study areas, 
While the third level and the third and fourth levels shall be the contrast a little for most of the study. except Mosul can note that there is considerable variation in volumetric soil water content readings at level three and four compared to other regions, in the city of Baghdad can be seen that the amount of volumetric water content of the soil at the third and fourth level are almost all months, compared with a fixed amount Basra, Mosul and Rutba also note that the volumetric soil water content value at the third level of the largest of its value soil at the fourth level in the areas of Baghdad, Basra and Rutba with the exception of Mosul where in the case of variation and for all levels of the soil.
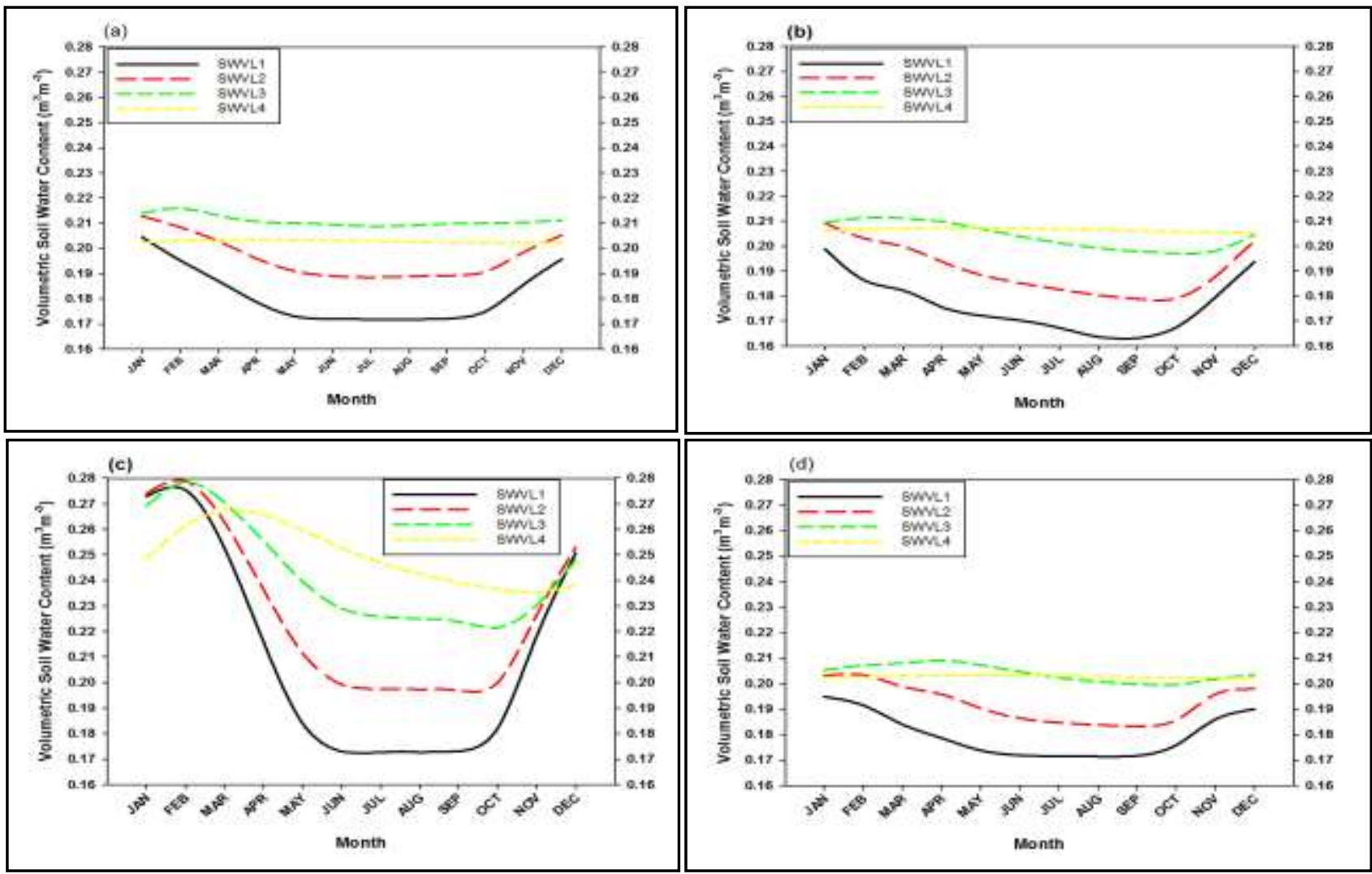

Figure 3. The monthly average for volumetric soil water content for four levels of soil for selected areas of Iraq from 1979 to 2011 (a) Baghdad, (b) Basra, (c) Mosul and (d) Rutba.

\section{B. Analysis of the General Behavior of Relative Humidity}

Shown in "Fig. 4", that the greatest value of the monthly average relative humidity have been recorded in Mosul in January monthly $79 \%$ and December $76 \%$ and the lowest value in Mosul also in July $24 \%$ and August $26 \%$.

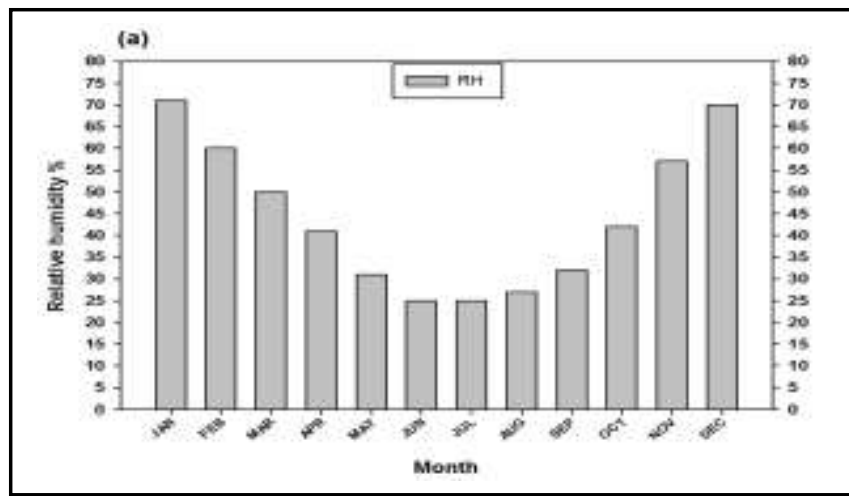

This is due to the difference in temperature between these months since when increasing temperatures decreasing relative humidity and this is evident in the months of July and August, while in January and December are the months of decreases in temperature and this increases the value of relative humidity.

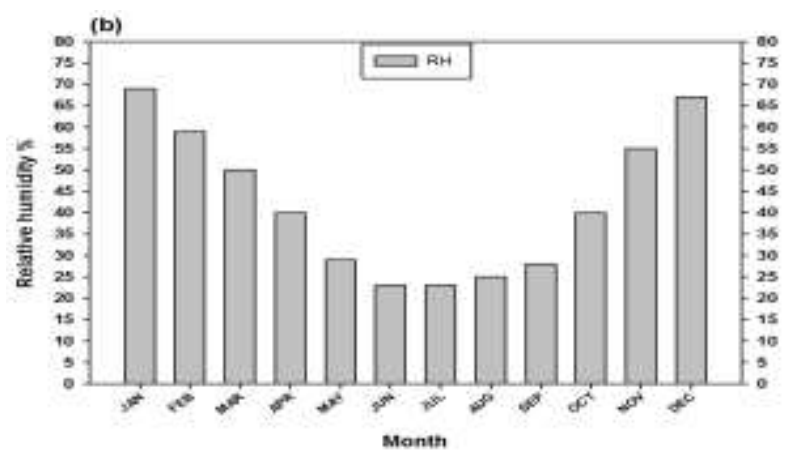




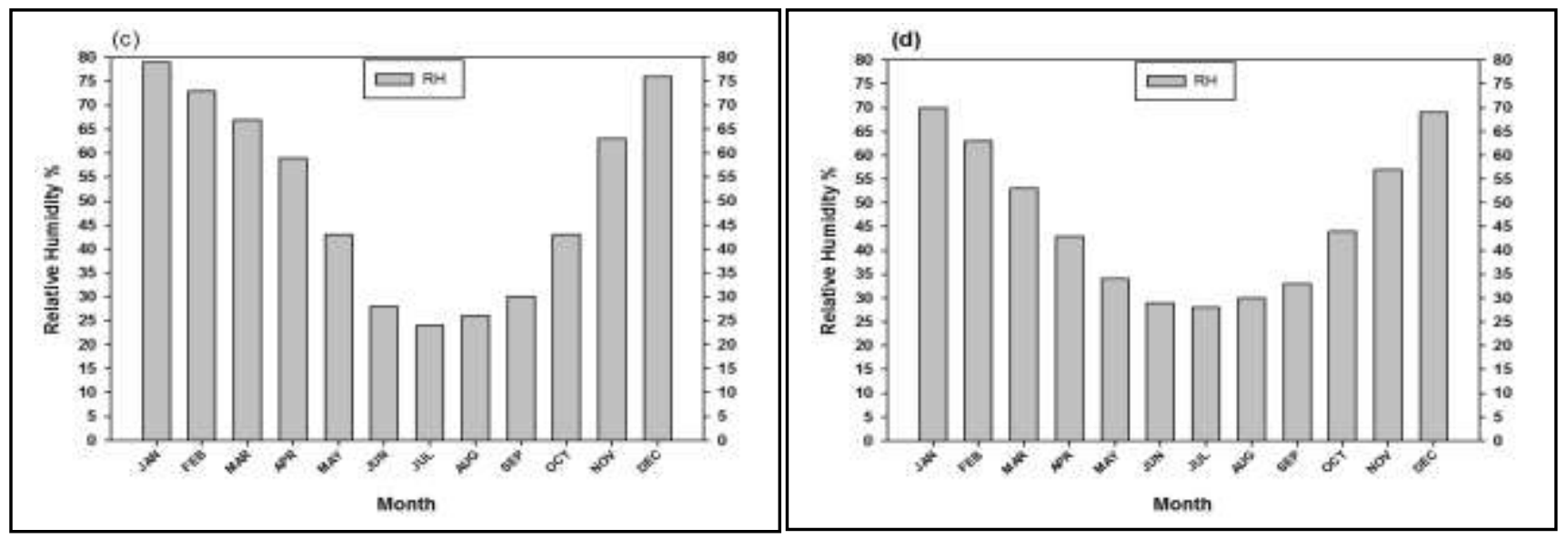

Figure 4. The monthly average for relative humidity of selected areas of Iraq for the period from 1979 to 2011(a) Baghdad, (b) Basra, (c) Mosul and (d) Rutba.

\section{Analysis of the General Behavior of the Surface Wind Speed}

The main source of wind energy is the incoming solar radiation that reaches the earth's surface where it is converted into energy of the wind, it is observed as shown in "Fig. 5", that the greatest value of the monthly average wind speed recorded in Basra, and the lowest values recorded in Mosul.
The reason for the difference in the temperatures between Basra and Mosul, which in turn leads to an increase in wind speed in Basra because of the high monthly average temperatures in Basra because of the different amount of incoming solar radiation per unit area in this region because of the difference in the region site for latitude, the greatest value of the monthly average wind speed has been recorded in Basra $6 \mathrm{~m} / \mathrm{sec}$ and the lowest value of the monthly average wind speed has been registered in Mosul $2.5 \mathrm{~m} / \mathrm{sec}$.

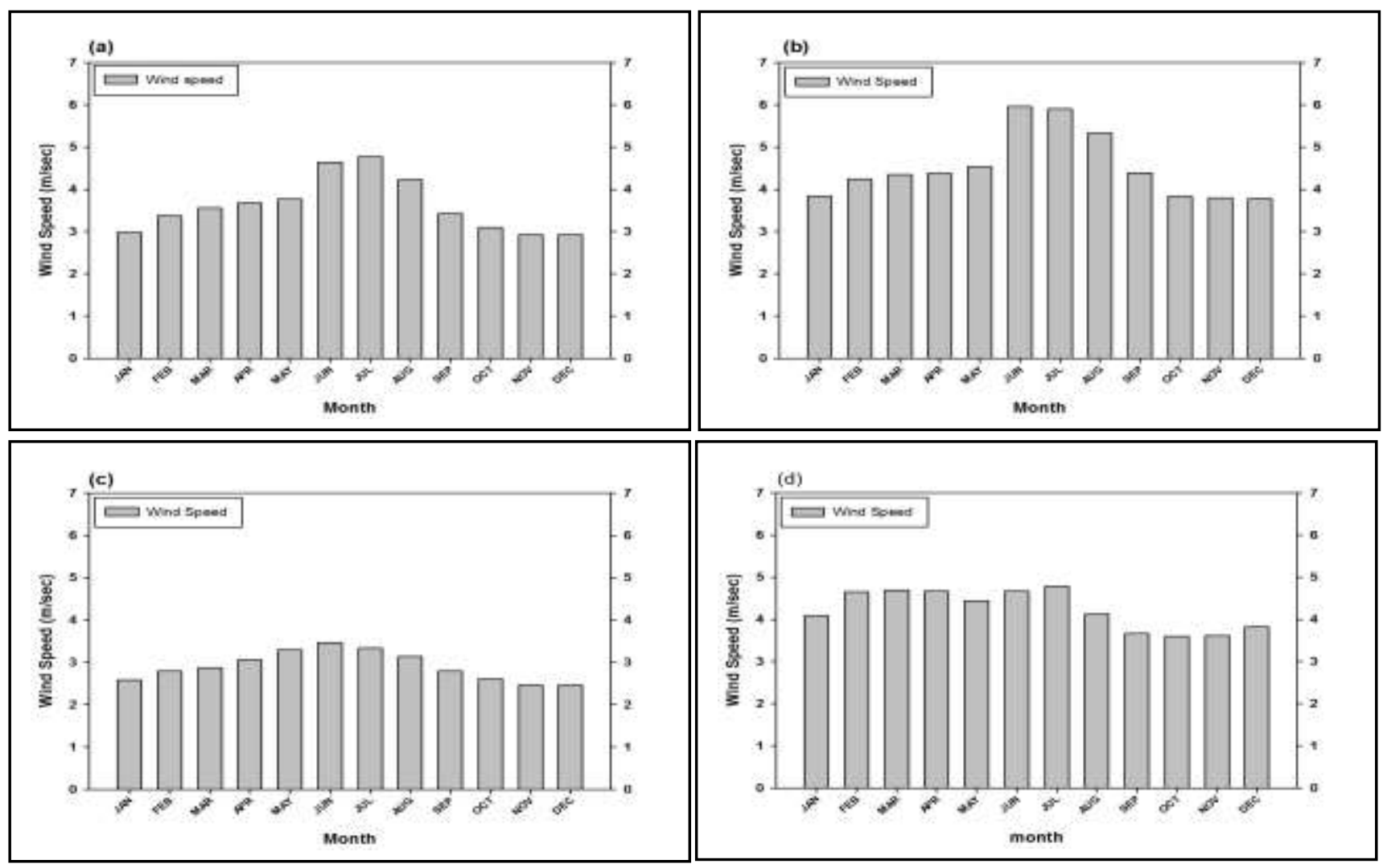

Figure 5. The monthly average for surface wind speed of selected areas of Iraq for the period from 1979 to 2011(a) Baghdad, (b) Basra, (c) Mosul and (d) Rutba. 


\section{vII. Relationship Between Some Meteorological Elements and Volumetric Soil Water Content}

\section{A. Volumetric Soil Water Content at the First Level (SWVL1)}

"Figures 6 to 9", that the volumetric water content of the soil at the first level (the first level from the soil that are at a depth of $(0.0-0.07$ meter $))$, in the case of an increase in all study areas during the 33 months of the year January, July and September. This is shown by the results of the correlation coefficient and both tests (Mann-Kendall and Spearman Rho) and the values of slope of the regression shown in the "Table 3", except Mosul in the case of a decrease in the month of January,
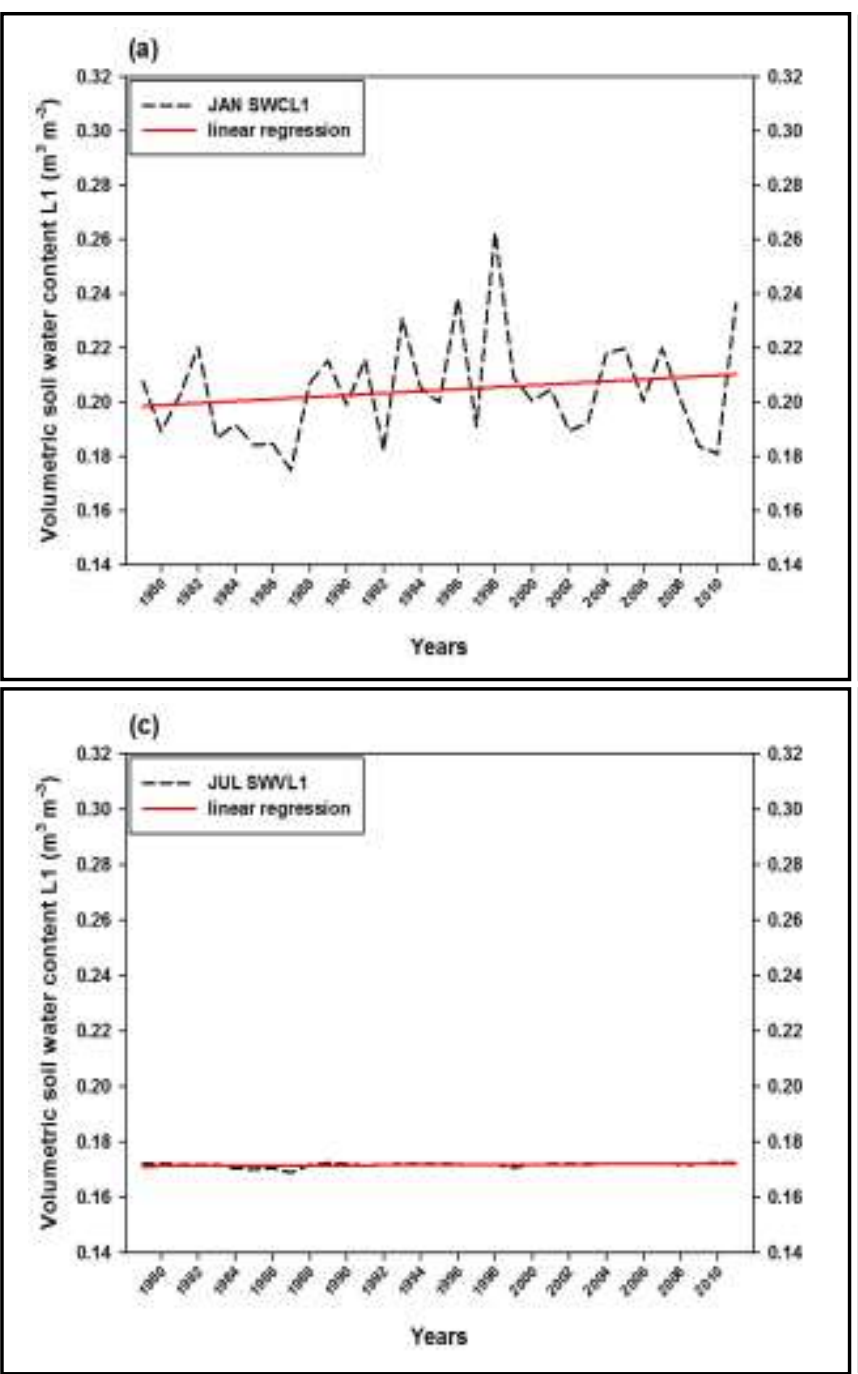

has recorded the greatest value for plants 0.3 and 0.4 in the month of September in Baghdad and Basra in the month of July and both tests in a row and were the values of P-value is relatively small 0.003 and 0.005 to Baghdad and Basra respectively, indicating that this change is a change in writing. In the month of March in the case of a decrease for all study areas recorded the greatest value of the correlation coefficient of -0.3 and -0.5 in Mosul and both tests in a row, while the value of the P-value was 0.007 also relatively small, suggesting that this change is a change in writing. The reason for the decline in the amount of volumetric soil water content in the month of January in Mosul to the soil type and height above sea level for this region characterized by not retaining water for a period of time long compared with the soil central and southern The decline happening in the month of March areas Baghdad, Basra and Rutba, it is due to the lack of rainfall in these areas, which affects the soil at this time precisely because it is one of the transitional months. If the values of P-value is relatively high in the month of January and all the study areas, suggesting that this change or worker is ineffective at this month during the study period.
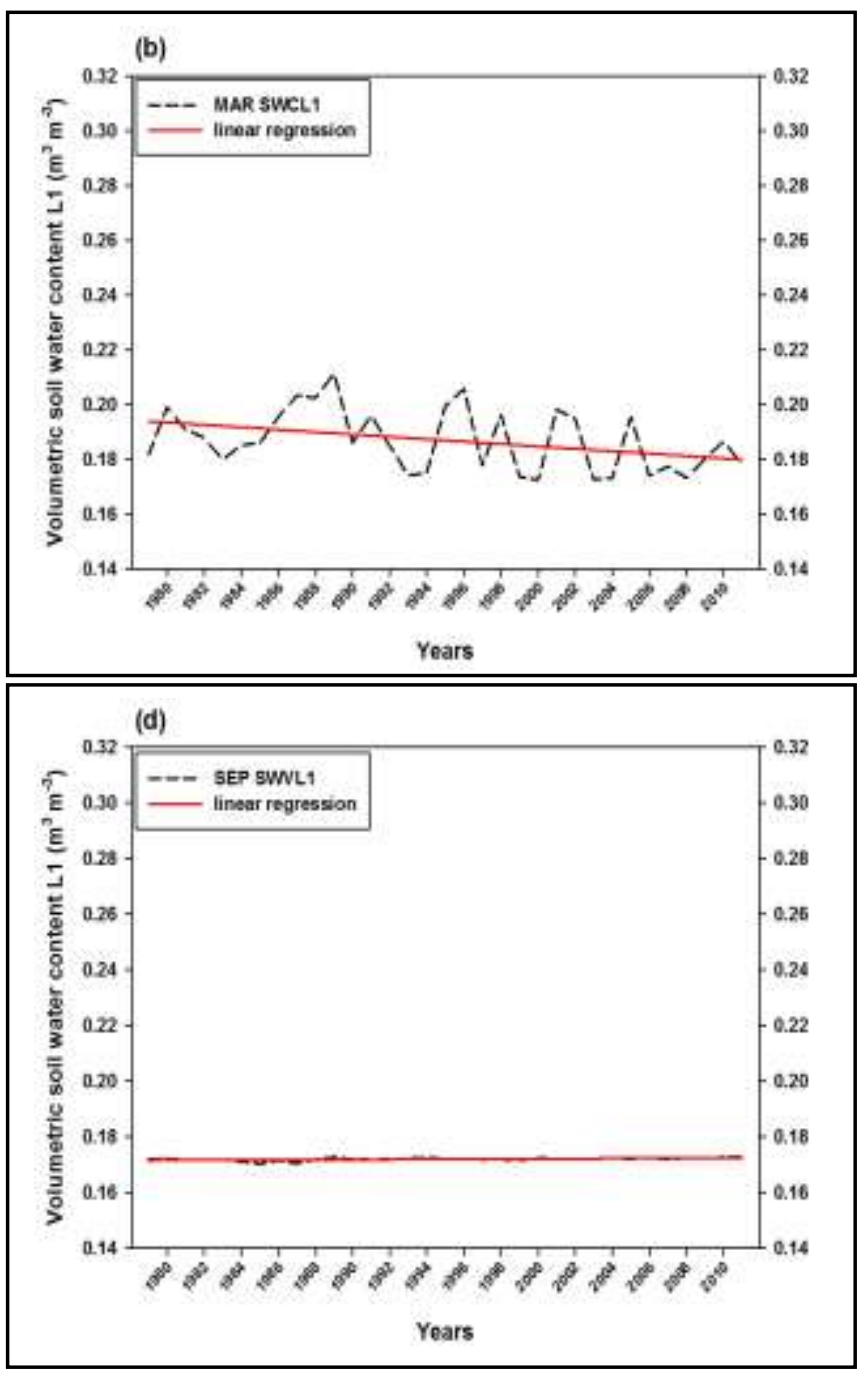

Figure 6. The annual average for volumetric soil water content for the first level of the soil of Baghdad city from 1979 to 2011 (a) January, (b) March, (c) July and (d) September. 
Proc. of the Second Intl. Conf. on Advances in Bio-Informatics and Environmental Engineering - ICABEE 2015 Copyright (C) Institute of Research Engineers and Doctors, USA .All rights reserved.

ISBN: 978-1-63248-043-9 doi: 10.15224/ 978-1-63248-043-9-107

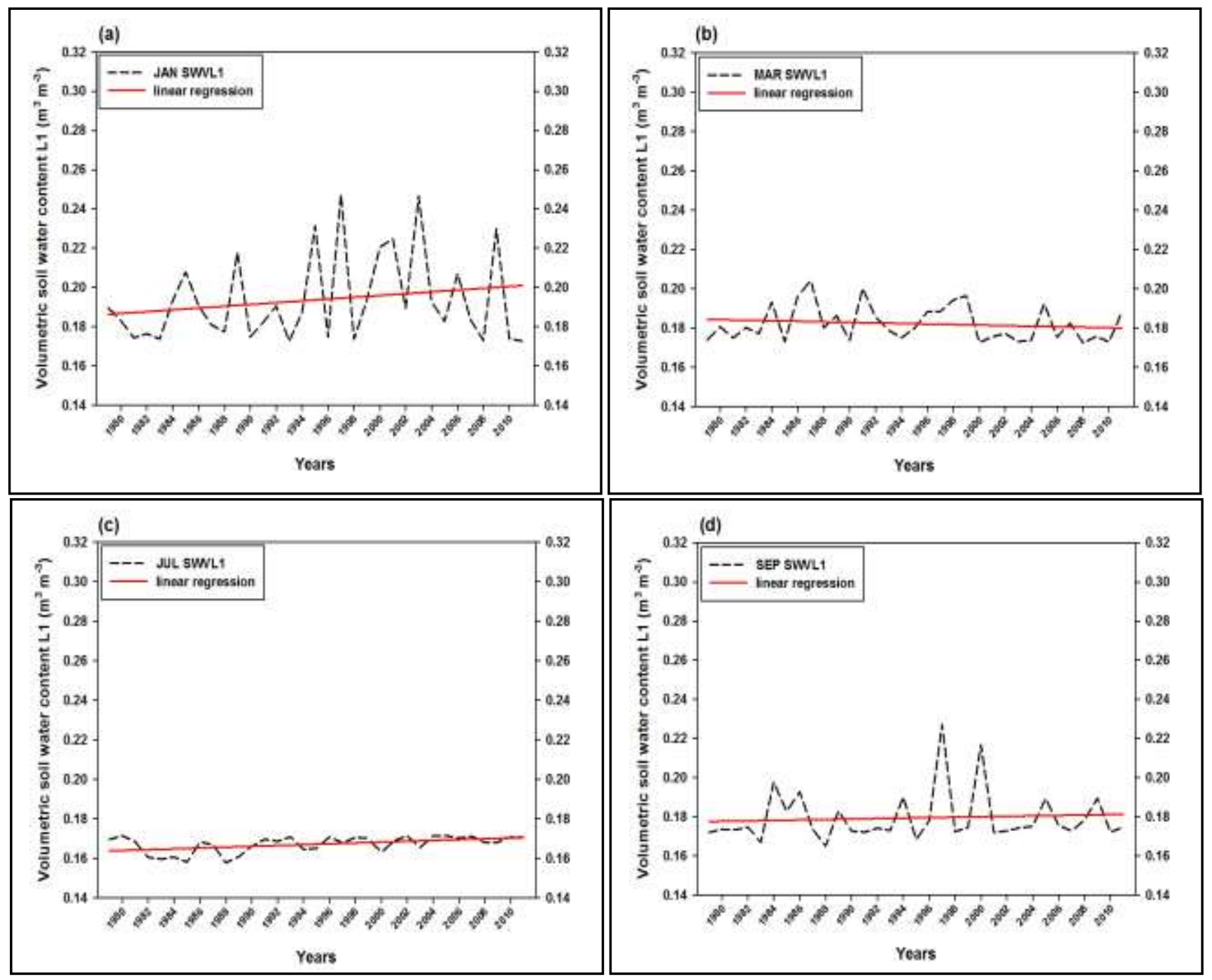

Figure 7. The annual average for volumetric soil water content for the first level of the soil of Basra city from 1979 to 2011 (a) January, (b) March, (c) July and (d) September.
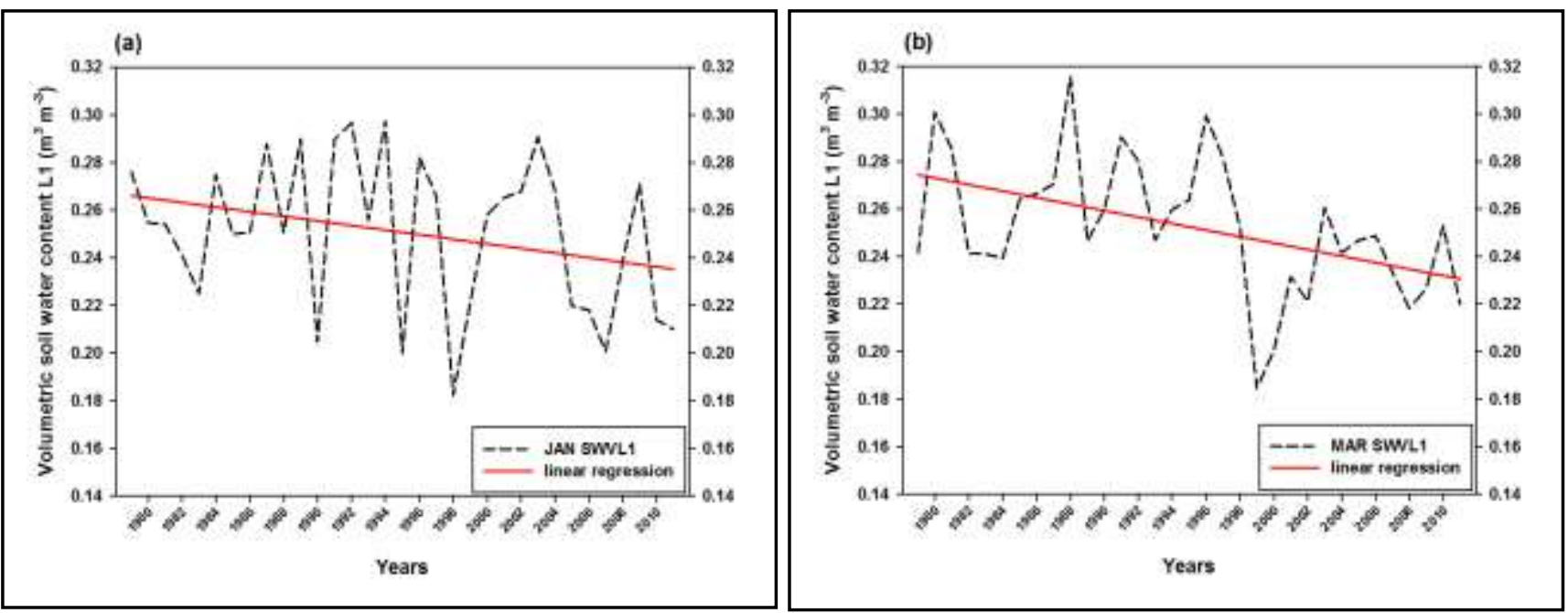
Proc. of the Second Intl. Conf. on Advances in Bio-Informatics and Environmental Engineering - ICABEE 2015 Copyright (C) Institute of Research Engineers and Doctors, USA .All rights reserved.

ISBN: 978-1-63248-043-9 doi: 10.15224/ 978-1-63248-043-9-107

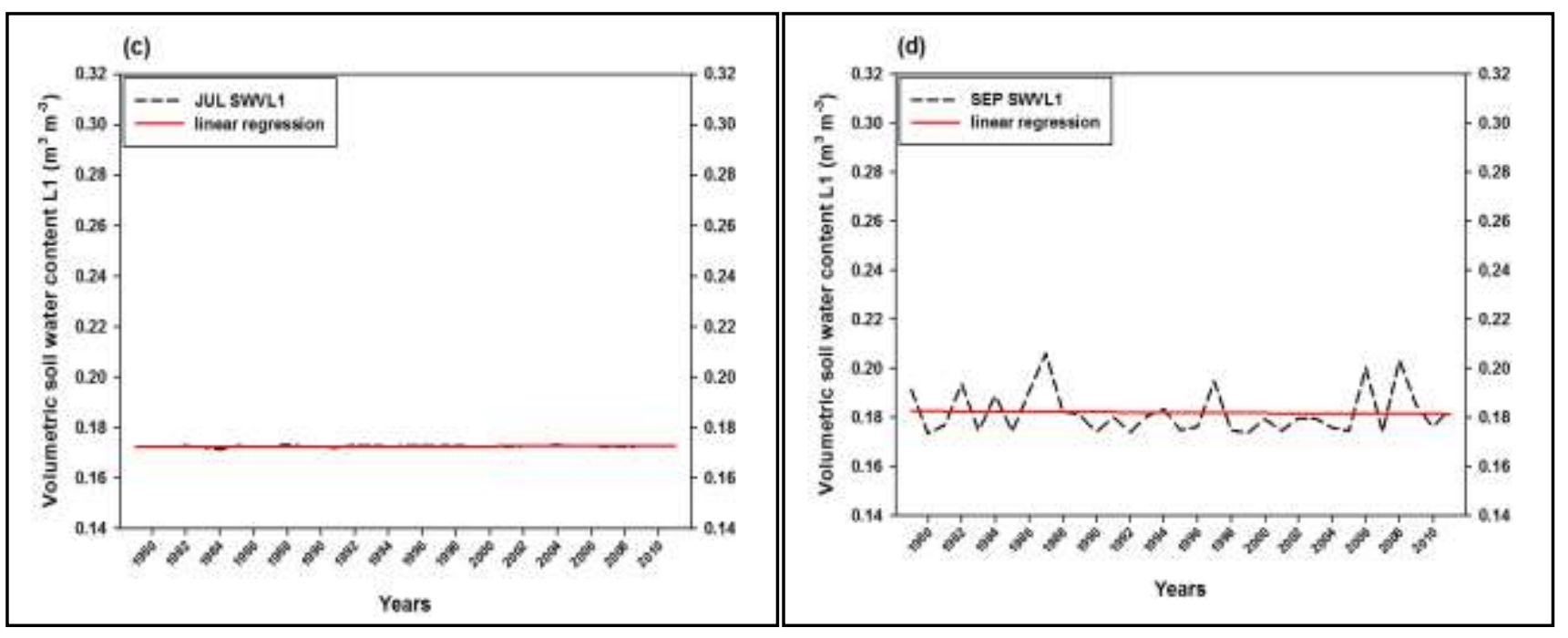

Figure 8. The annual average for volumetric soil water content for the first level of the soil of Mosul city from 1979 to 2011 (a) January, (b) March, (c) July and (d) September.
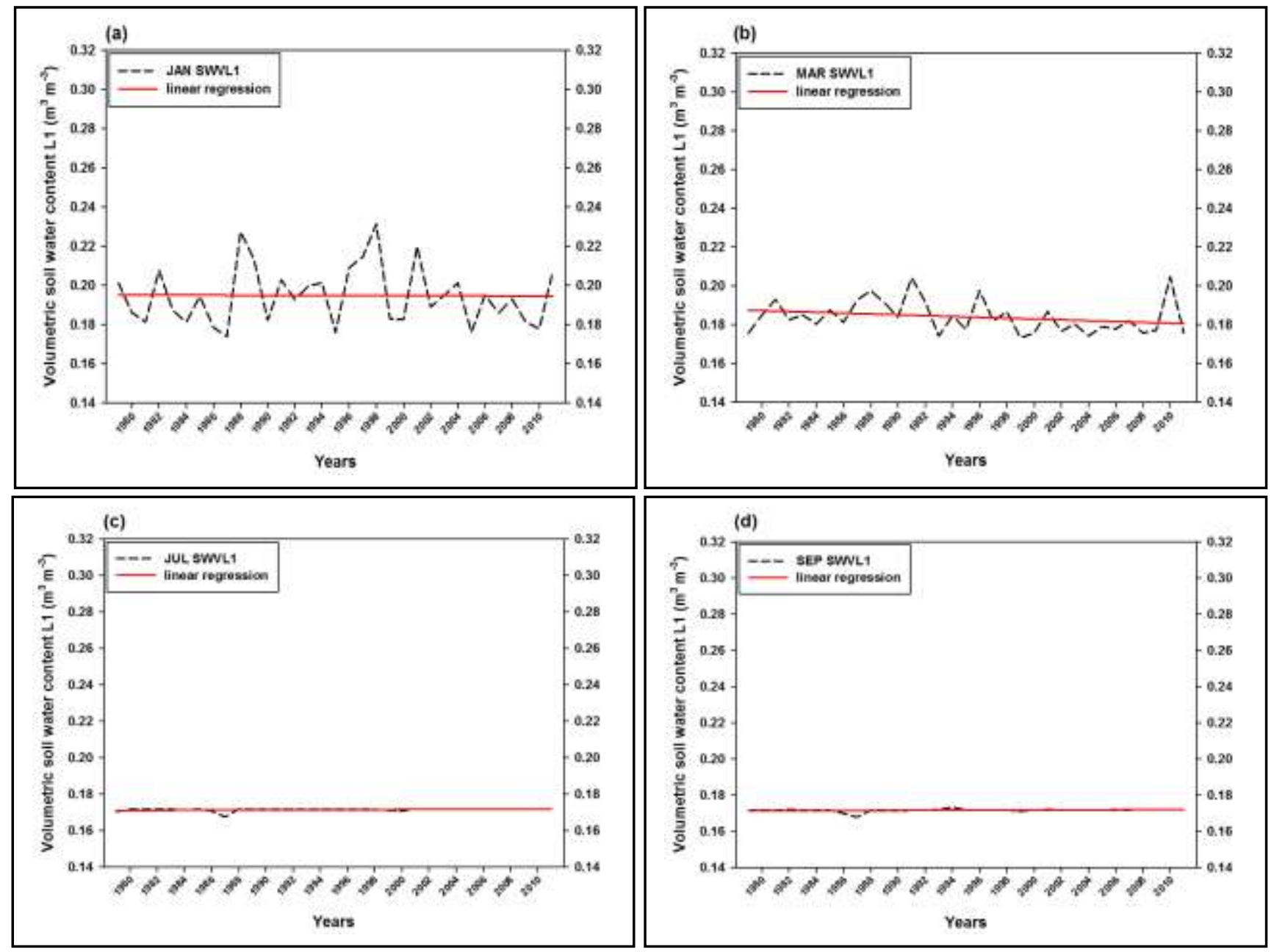

Figure 9. The annual average for volumetric soil water content for the first level of the soil of Rutba city from 1979 to 2011 (a) January, (b) March, (c) July and (d) September. 
Proc. of the Second Intl. Conf. on Advances in Bio-Informatics and Environmental Engineering - ICABEE 2015 Copyright (C) Institute of Research Engineers and Doctors, USA .All rights reserved.

ISBN: 978-1-63248-043-9 doi: 10.15224/ 978-1-63248-043-9-107

TABLE 3. Results of tests (Mann-Kendall, Spearman Rho) and simple linear regression to test the orientation of volumetric soil water content for the first level of the soil at depth (0.0 - 0.07 meter), months (January, March, July and September) areas (Baghdad, Basra, Mosul and Rutba).

\begin{tabular}{|c|c|c|c|c|c|c|c|c|}
\hline \multirow{2}{*}{ Months } & \multirow{2}{*}{ Areas } & \multicolumn{2}{|c|}{ Mann-Kendall Test } & \multicolumn{2}{|c|}{ Spearman Rho Test } & \multicolumn{3}{|c|}{ Simple Linear Regression } \\
\hline & & $\tau$ & Correlation & $\mathbf{r}_{\mathrm{s}}$ & Correlation & Slope & P-Value & Relationship \\
\hline \multirow{4}{*}{ January } & Baghdad & 0.1 & Extrusive slightly & 0.2 & Extrusive few & 0.0004 & 0.3 & No linear \\
\hline & Basra & 0.1 & Extrusive slightly & 0.1 & Extrusive slightly & 0.0005 & 0.3 & No linear \\
\hline & Mosul & -0.2 & Reverse few & -0.3 & Reverse few & -0.001 & 0.1 & No linear \\
\hline & Rutba & -0.01 & No correlation & -0.02 & No correlation & -0.00001 & 0.9 & No linear \\
\hline \multirow{4}{*}{ March } & Baghdad & -0.3 & Reverse few & -0.4 & Reverse medium & -0.0004 & 0.03 & Linear \\
\hline & Basra & -0.1 & Reverse slightly & -0.2 & Reverse few & -0.0001 & 0.4 & No linear \\
\hline & Mosul & -0.3 & Reverse few & -0.5 & Reverse medium & -0.001 & 0.007 & Linear \\
\hline & Rutba & -0.2 & Reverse few & -0.3 & Reverse few & -0.0002 & 0.2 & No linear \\
\hline \multirow{4}{*}{ July } & Baghdad & 0.3 & Extrusive few & 0.3 & Extrusive few & 0.00003 & 0.03 & Linear \\
\hline & Basra & 0.3 & Extrusive few & 0.4 & Extrusive medium & 0.0002 & 0.005 & Linear \\
\hline & Mosul & 0.3 & Extrusive few & 0.3 & Extrusive few & 0.00001 & 0.09 & Linear \\
\hline & Rutba & 0.2 & Extrusive few & 0.3 & Extrusive few & 0.00002 & 0.1 & No linear \\
\hline \multirow{4}{*}{ September } & Baghdad & 0.3 & Extrusive few & 0.4 & Extrusive medium & 0.00003 & 0.003 & Linear \\
\hline & Basra & 0.1 & Extrusive slightly & 0.2 & Extrusive few & 0.0001 & 0.6 & No linear \\
\hline & Mosul & -0.01 & No correlation & 0.01 & No correlation & -0.00003 & 0.8 & No linear \\
\hline & Rutba & 0.1 & Extrusive slightly & 0.1 & Extrusive slightly & 0.00002 & 0.2 & No linear \\
\hline
\end{tabular}

\section{B. Relationship Between Relative Humidity and Volumetric Soil Water Content}

Relative humidity relationship volumetric water content of the soil at the first level, described in the "Figures 10 to 13 ", and "Table 4", is a direct correlation medium to high when months January and March for all study areas and clarified through correlation coefficients values and the tendency of positive gradient greatest value was recorded for the coefficient of 0.6 and 0.7 in the month of January in the Rutba, but both tests Mann-Kendall and Spearman rho ranks respectively, and this shows that the relative humidity relationship with the volumetric soil water content is correlate an increase of relative humidity decreases the amount of water evaporation from the soil as a result of saturation of the air with water vapor, and thus leads to a lack of water loss from the soil, but when you decrease the amount of humidity in the air, it is leading to an increase in the evaporation of water from the soil process and thus lead to a decrease in the amount of volumetric soil water content. In the months July and September, there is no linear relationship between volumetric soil water content and relative humidity for all study areas, and this is evident through the value of high lowlying link and the high values of $\mathrm{P}$-value, as the minimum value of the correlation coefficient 0.05 and 0.05 have been recorded in Basra in July and both tests Mann-Kendall and Spearman rho ranks respectively, and higher values of $\mathrm{P}$-value was also recorded in Basra 0.9 in July.
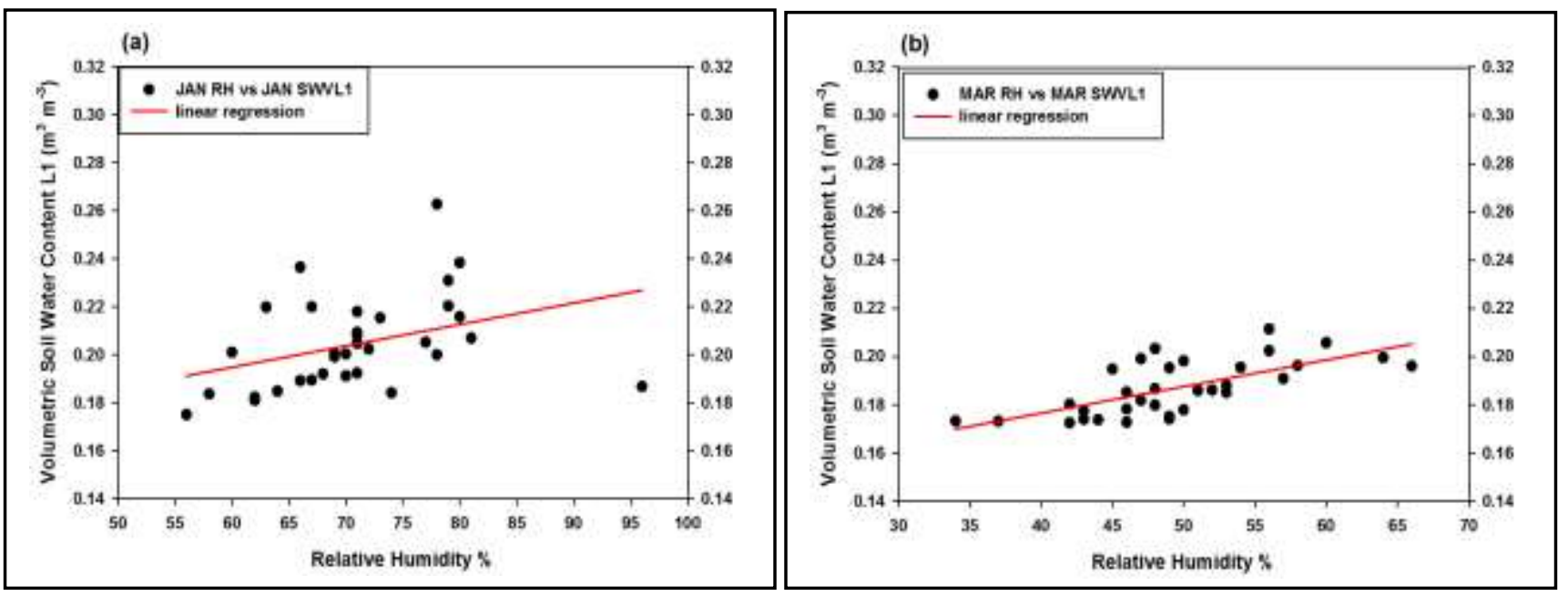
Proc. of the Second Intl. Conf. on Advances in Bio-Informatics and Environmental Engineering - ICABEE 2015 Copyright (C) Institute of Research Engineers and Doctors, USA .All rights reserved.

ISBN: 978-1-63248-043-9 doi: 10.15224/ 978-1-63248-043-9-107
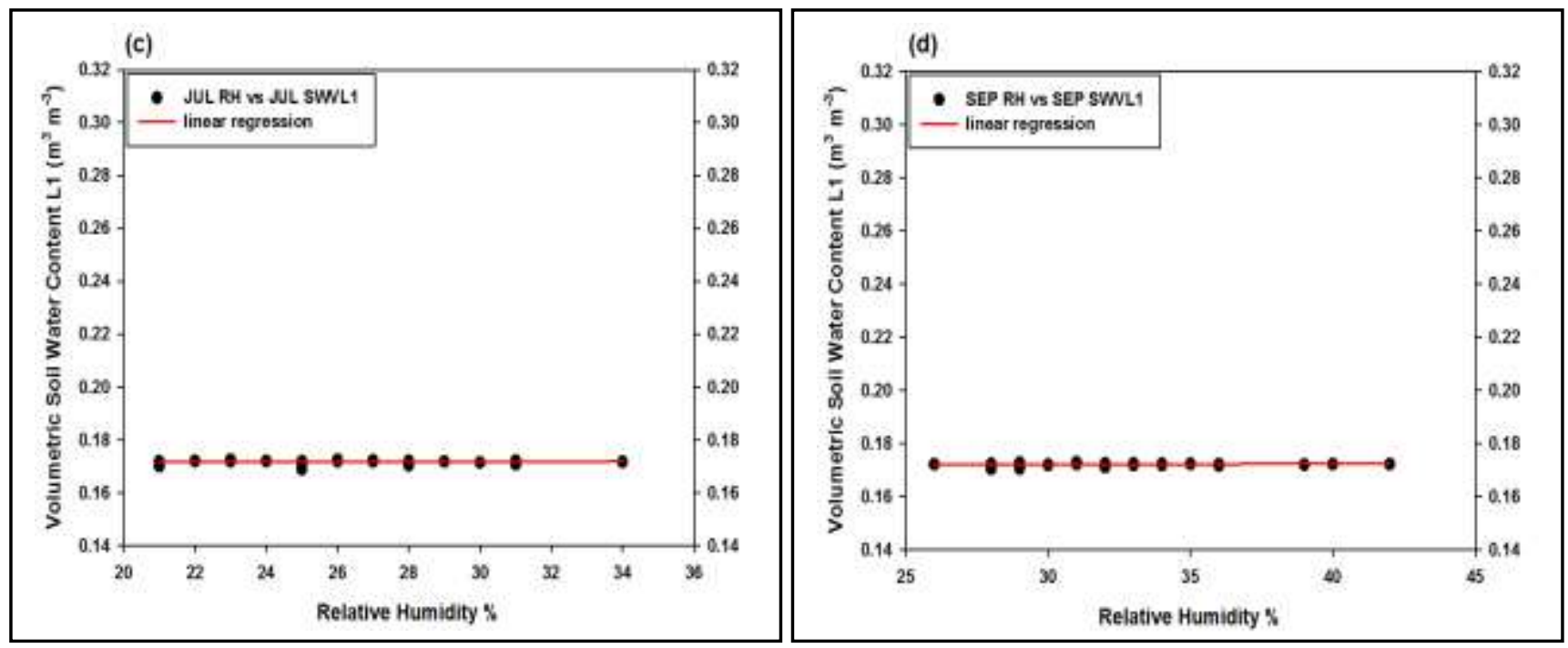

Figure 10. The relationship between relative humidity and volumetric soil water content for the first level of the soil of Baghdad city from 1979 to 2011 (a) January, (b) March, (c) July and (d) September.
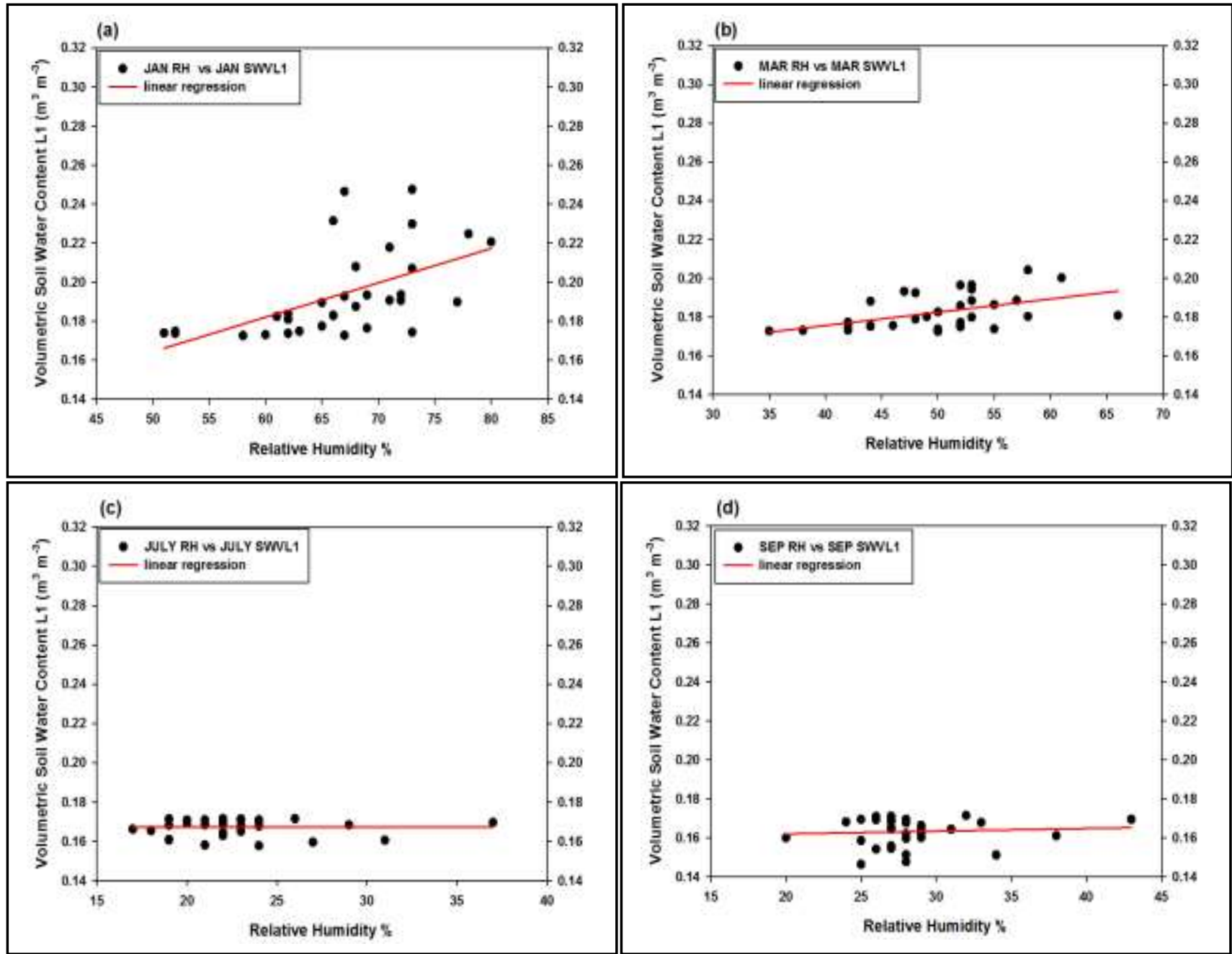

Figure 11. The relationship between relative humidity and volumetric soil water content for the first level of the soil of Basra city from 1979 to 2011 (a) January, (b) March, (c) July and (d) September. 
Proc. of the Second Intl. Conf. on Advances in Bio-Informatics and Environmental Engineering - ICABEE 2015 Copyright (C) Institute of Research Engineers and Doctors, USA .All rights reserved.

ISBN: 978-1-63248-043-9 doi: 10.15224/ 978-1-63248-043-9-107

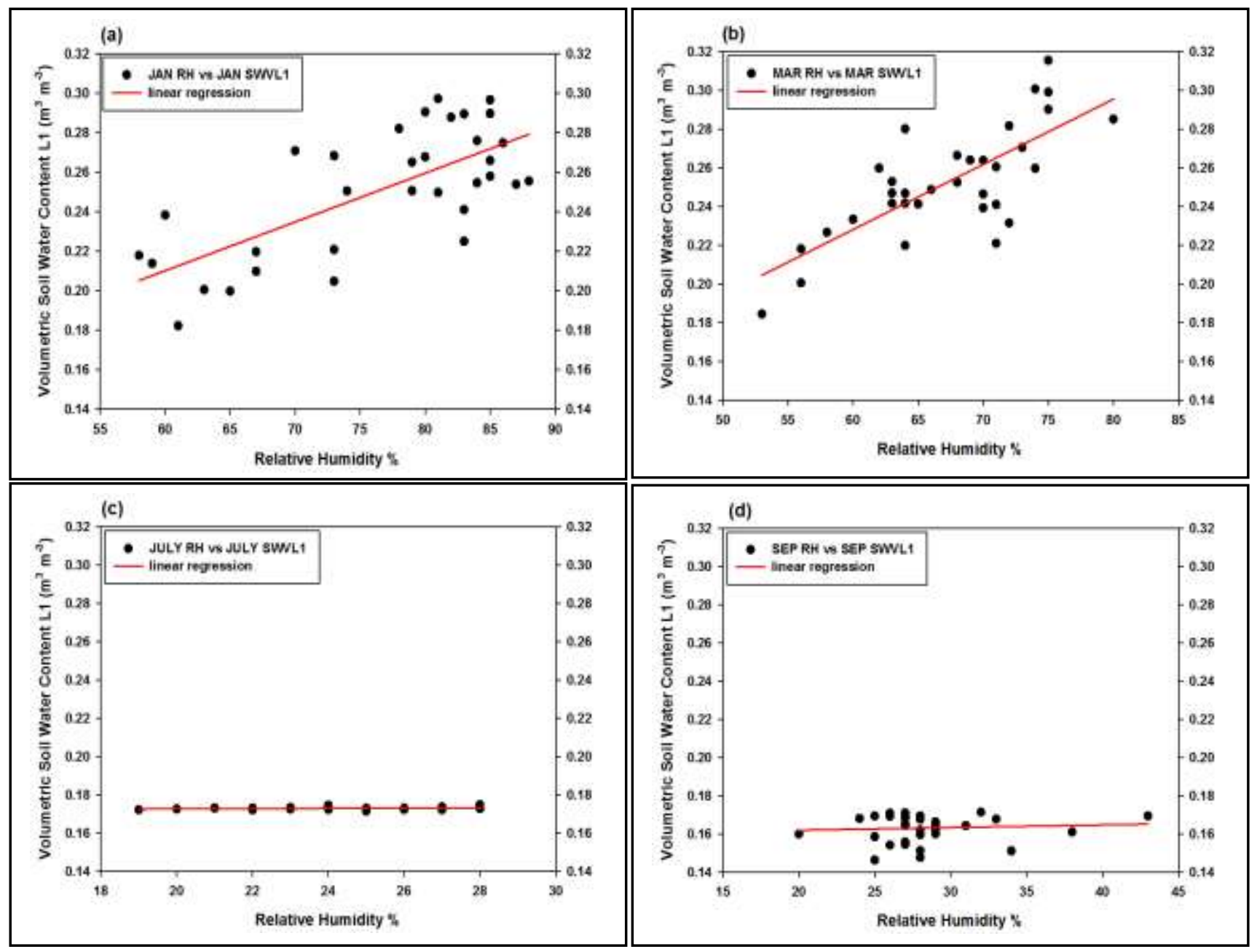

Figure 12. The relationship between relative humidity and volumetric soil water content for the first level of the soil of Mosul city from 1979 to 2011 (a) January, (b) March, (c) July and (d) September.
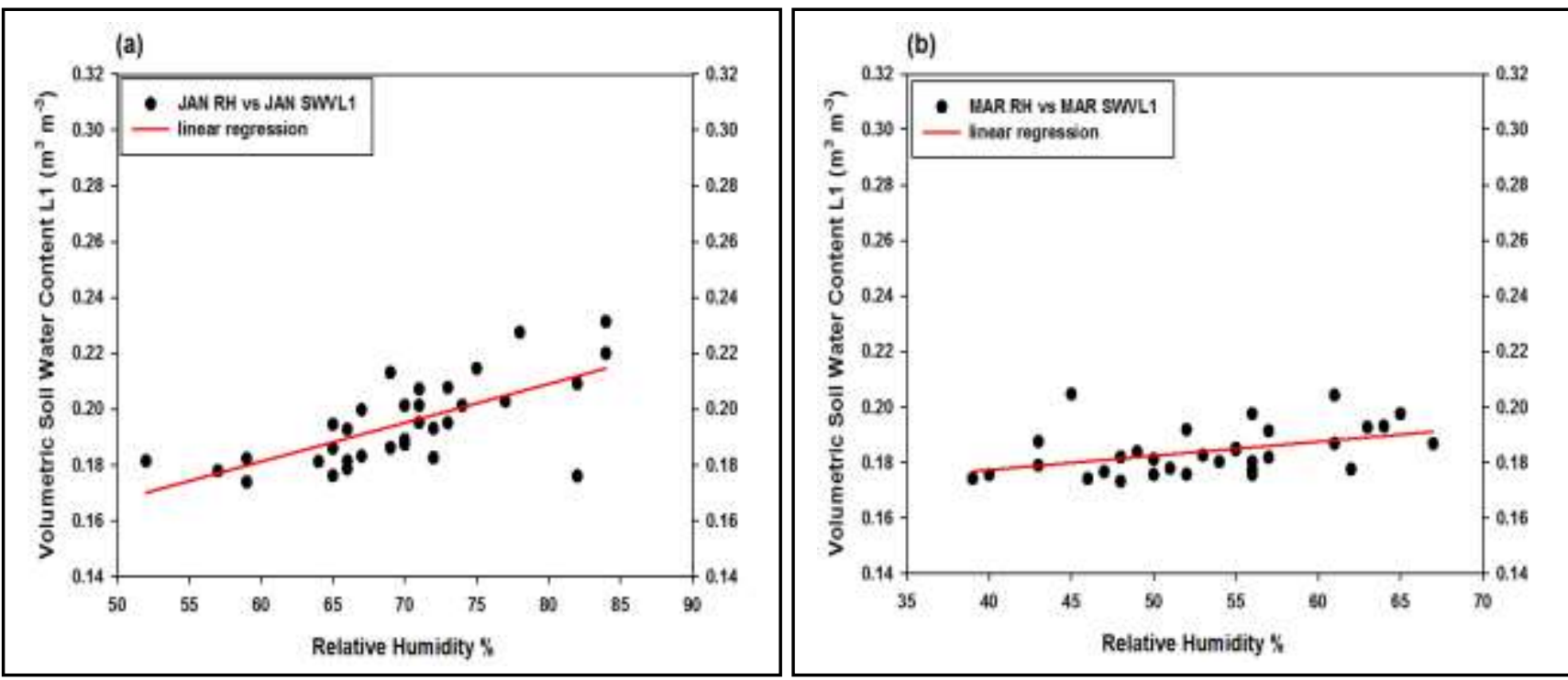

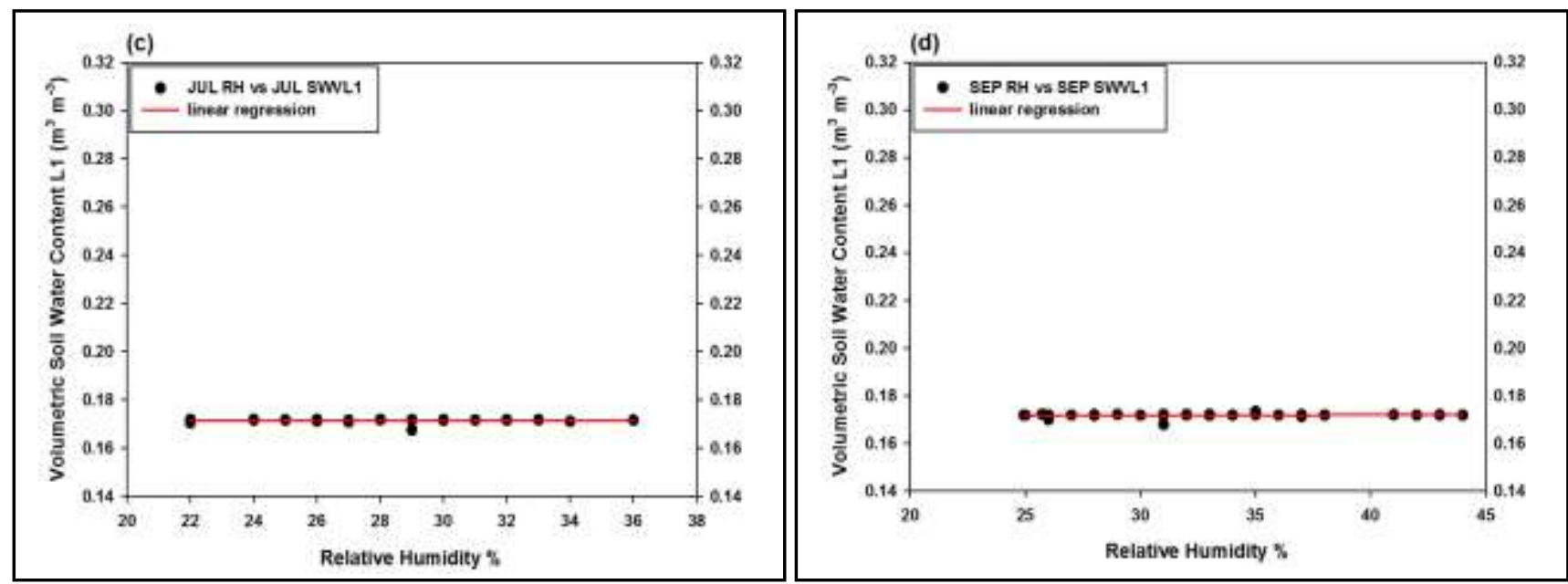

Figure 13. The relationship between relative humidity and volumetric soil water content for the first level of the soil of Rutba city from 1979 to 2011 (a) January, (b) March, (c) July and (d) September.

TABLE 4. Results of tests (Mann-Kendall, Spearman Rho) and simple linear regression to test the strength of the relationship between relative humidity and volumetric soil water content at the first level of the soil at depth (0.0 - 0.07 meter), months (January, March, July and September) areas (Baghdad, Basra, Mosul and Rutba).

\begin{tabular}{|c|c|c|c|c|c|c|c|c|}
\hline \multirow{2}{*}{ Months } & \multirow{2}{*}{ Areas } & \multicolumn{2}{|c|}{ Mann-Kendall Test } & \multicolumn{2}{|c|}{ Spearman Rho Test } & \multicolumn{3}{|c|}{ Simple Linear Regression } \\
\hline & & $\tau$ & Correlation & $\mathbf{r}_{\mathrm{s}}$ & Correlation & Slope & P-Value & Relationship \\
\hline \multirow{4}{*}{ January } & Baghdad & 0.4 & Extrusive medium & 0.5 & Extrusive medium & 0.0009 & 0.03 & Linear \\
\hline & Basra & 0.5 & Extrusive medium & 0.7 & Extrusive high & 0.0018 & 0.0007 & Linear \\
\hline & Mosul & 0.4 & Extrusive medium & 0.6 & Extrusive medium & 0.003 & $<0.0001$ & Linear \\
\hline & Rutba & 0.6 & Extrusive medium & 0.7 & Extrusive high & 0.0014 & $<0.0001$ & Linear \\
\hline \multirow{4}{*}{ March } & Baghdad & 0.5 & Extrusive medium & 0.7 & extrusive high & 0.0011 & $<0.0001$ & Linear \\
\hline & Basra & 0.4 & Extrusive medium & 0.6 & Extrusive medium & 0.0007 & 0.003 & Linear \\
\hline & Mosul & 0.5 & Extrusive medium & 0.7 & Extrusive high & 0.0034 & $<0.0001$ & Linear \\
\hline & Rutba & 0.4 & Extrusive medium & 0.5 & Extrusive medium & 0.0005 & 0.01 & Linear \\
\hline \multirow{4}{*}{ July } & Baghdad & -0.07 & No correlation & -0.08 & No correlation & 0.00001 & 0.7 & No linear \\
\hline & Basra & 0.05 & No correlation & 0.05 & No correlation & 0.000001 & 0.9 & No linear \\
\hline & Mosul & 0.1 & Extrusive slightly & 0.2 & Extrusive few & 0.00008 & 0.1 & No linear \\
\hline & Rutba & -0.08 & No correlation & -0.09 & No correlation & -0.000002 & 0.9 & No linear \\
\hline \multirow{4}{*}{ September } & Baghdad & 0.1 & Extrusive slightly & 0.2 & Extrusive few & 0.00003 & 0.3 & No linear \\
\hline & Basra & 0.05 & No correlation & 0.07 & No correlation & 0.0001 & 0.7 & No linear \\
\hline & Mosul & -0.1 & Extrusive few & -0.2 & Extrusive few & -0.00002 & 0.2 & No linear \\
\hline & Rutba & 0.1 & Extrusive slightly & 0.2 & Extrusive few & 0.00002 & 0.4 & No linear \\
\hline
\end{tabular}

\section{c. Relationship Between Surface Wind Speed and Volumetric Soil Water Content}

The form of the relationship between the surface wind speed and the volumetric soil water content for the first level of the soil are described in the "Figures 14 to 17" and "Table 5 ", is an inverse relationship to the medium at a few months January and March areas Baghdad and Basra, has recorded the greatest value for the correlation coefficient of -0.3 and -0.4 in Basra in the month of January, but both tests Mann-Kendall and Spearman rho ranks respectively, while in the months July and September, there is no linear relationship between wind speed and volumetric water content of the soil, it has the lowest value of the correlation coefficient in Basra in
September 0.0, -0.02, and both tests Mann-Kendall and Spearman rho ranks respectively. The Mosul and Rutba, the behavior of volumetric soil water content direct impact is influenced by wind speed as decreasing volumetric soil water content increase of wind speed and vice versa, is evident in the month of January in the Rutba becomes the relationship is a positive medium, as are 0.4 and 0.5 correlation coefficients value for both tests Mann-Kendall and Spearman rho ranks respectively. In the months March, July and September, there is no linear relationship between the surface wind speed and the volumetric soil water content, and this is evident through the correlation coefficients values, where the lowest value of the correlation coefficient -0.01 in Mosul in September and both tests Mann-Kendall and Spearman rho ranks, and this is also evident through the slope of the regression values and the high value of $\mathrm{P}$-value 0.9 . 
Proc. of the Second Intl. Conf. on Advances in Bio-Informatics and Environmental Engineering - ICABEE 2015 Copyright (C) Institute of Research Engineers and Doctors, USA .All rights reserved.

ISBN: 978-1-63248-043-9 doi: 10.15224/ 978-1-63248-043-9-107
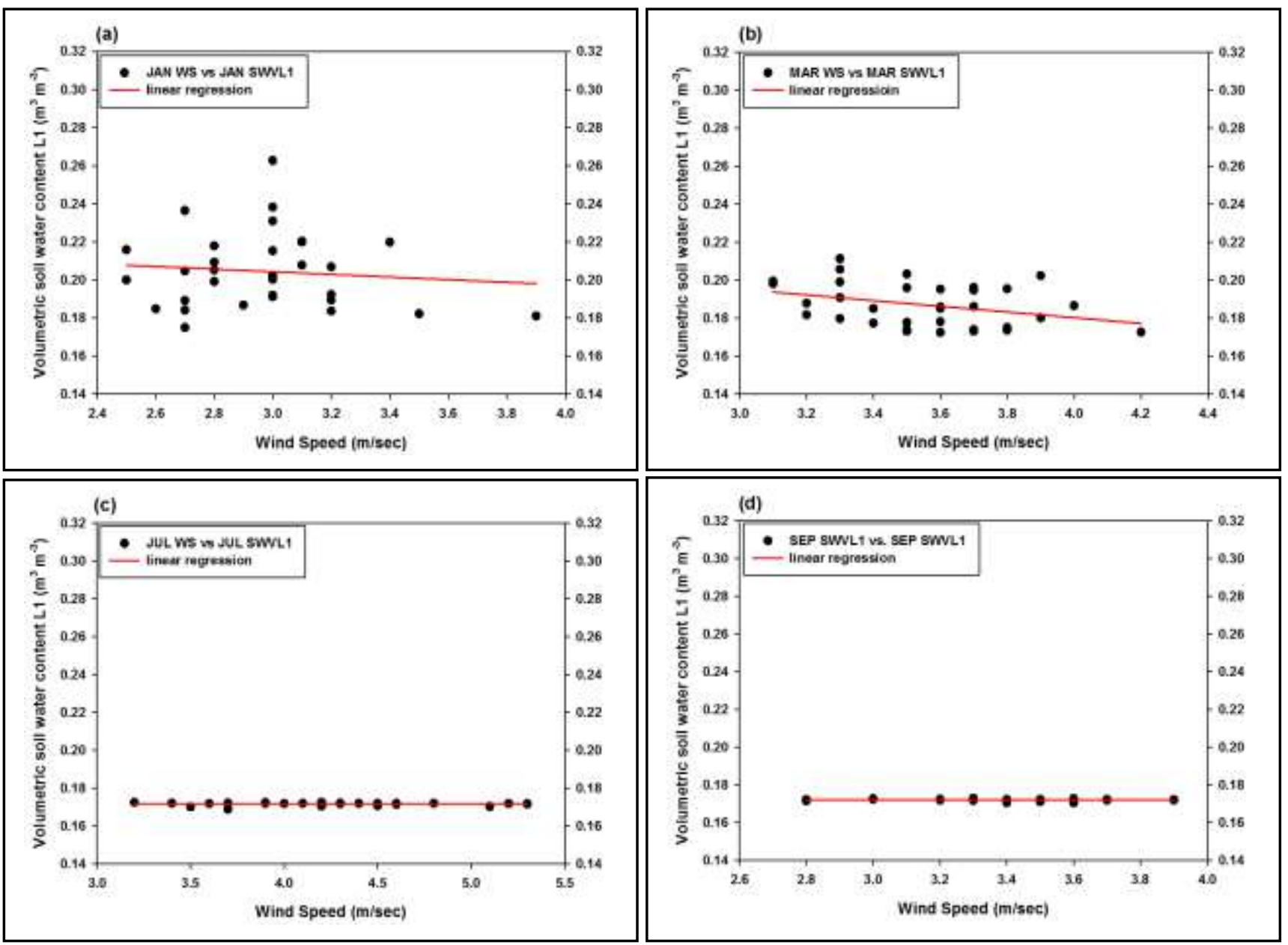

Figure 14. The relationship between surface wind speed and volumetric soil water content for the first level of the soil of Baghdad city from 1979 to 2011 (a) January, (b) March, (c) July and (d) September.

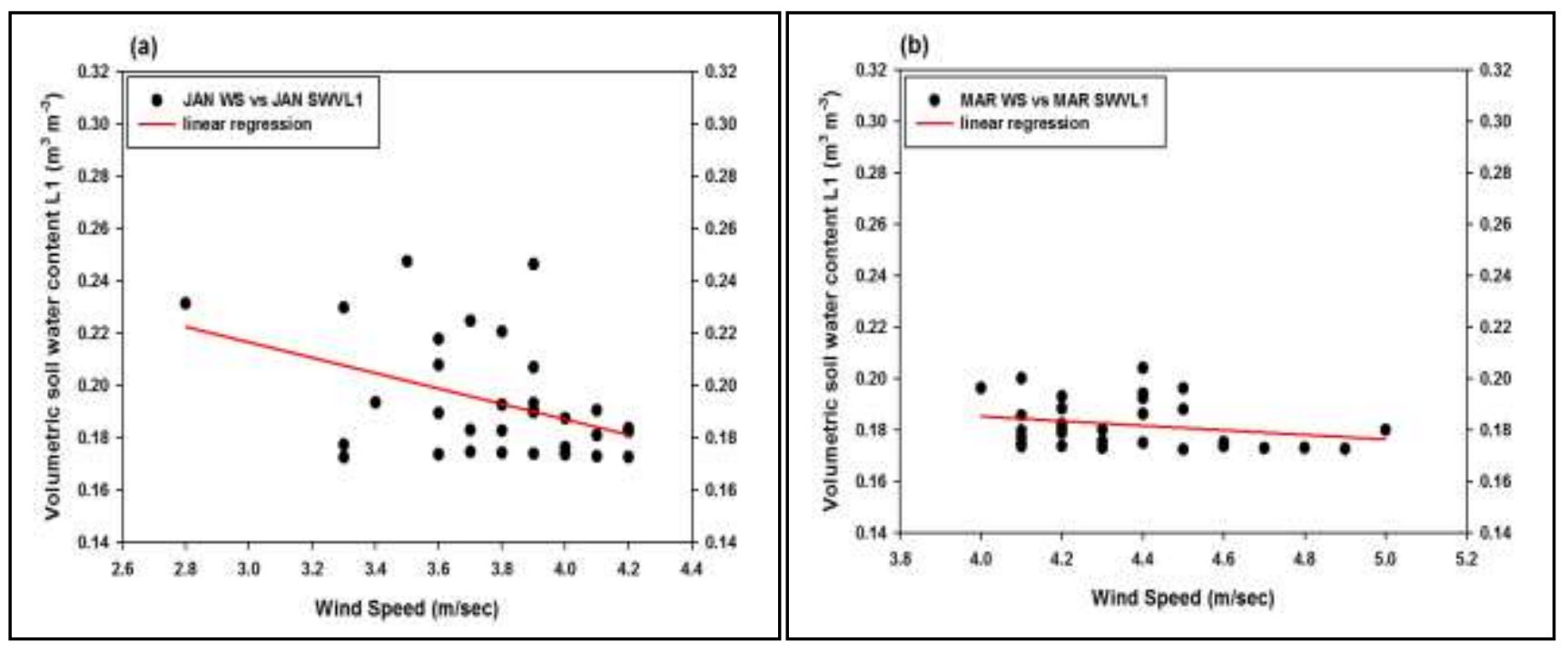


Proc. of the Second Intl. Conf. on Advances in Bio-Informatics and Environmental Engineering - ICABEE 2015 Copyright (C) Institute of Research Engineers and Doctors, USA .All rights reserved.

ISBN: 978-1-63248-043-9 doi: 10.15224/ 978-1-63248-043-9-107
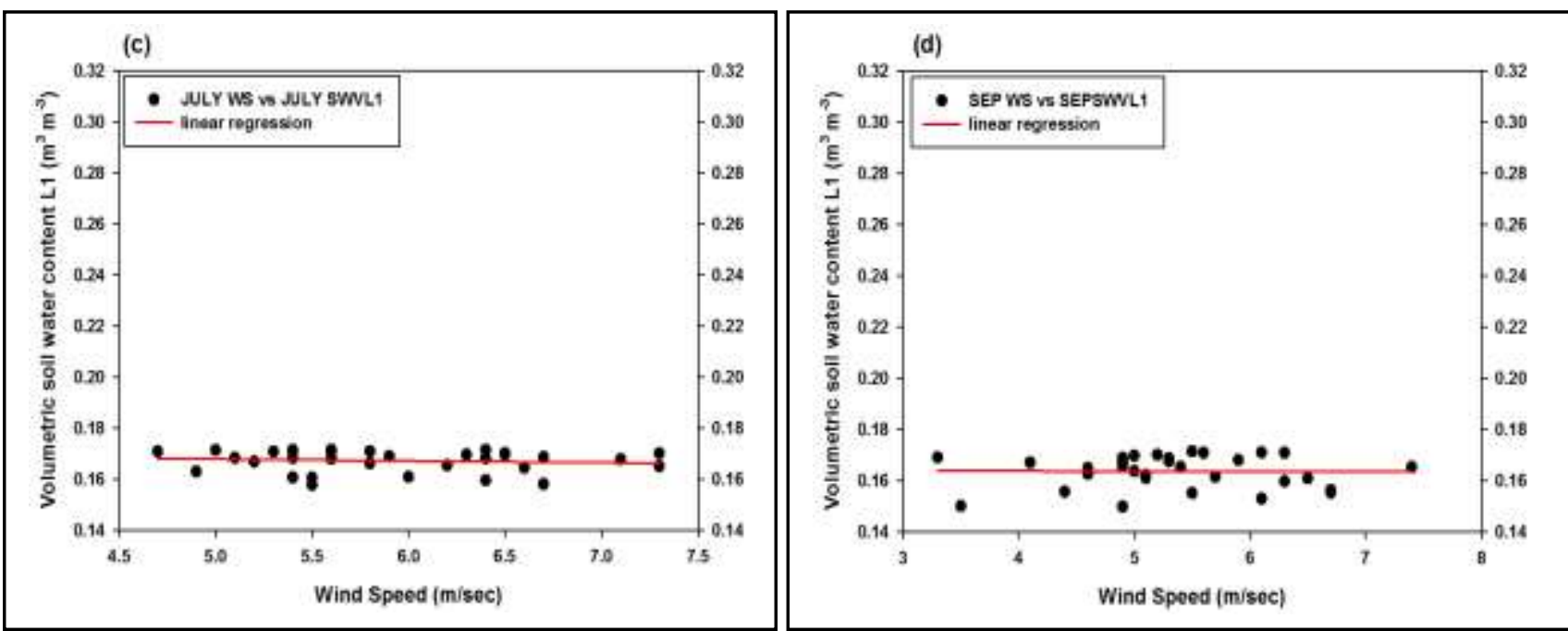

Figure 15. The relationship between surface wind speed and volumetric soil water content for the first level of the soil of Basra city from 1979 to 2011 (a) January, (b) March, (c) July and (d) September.
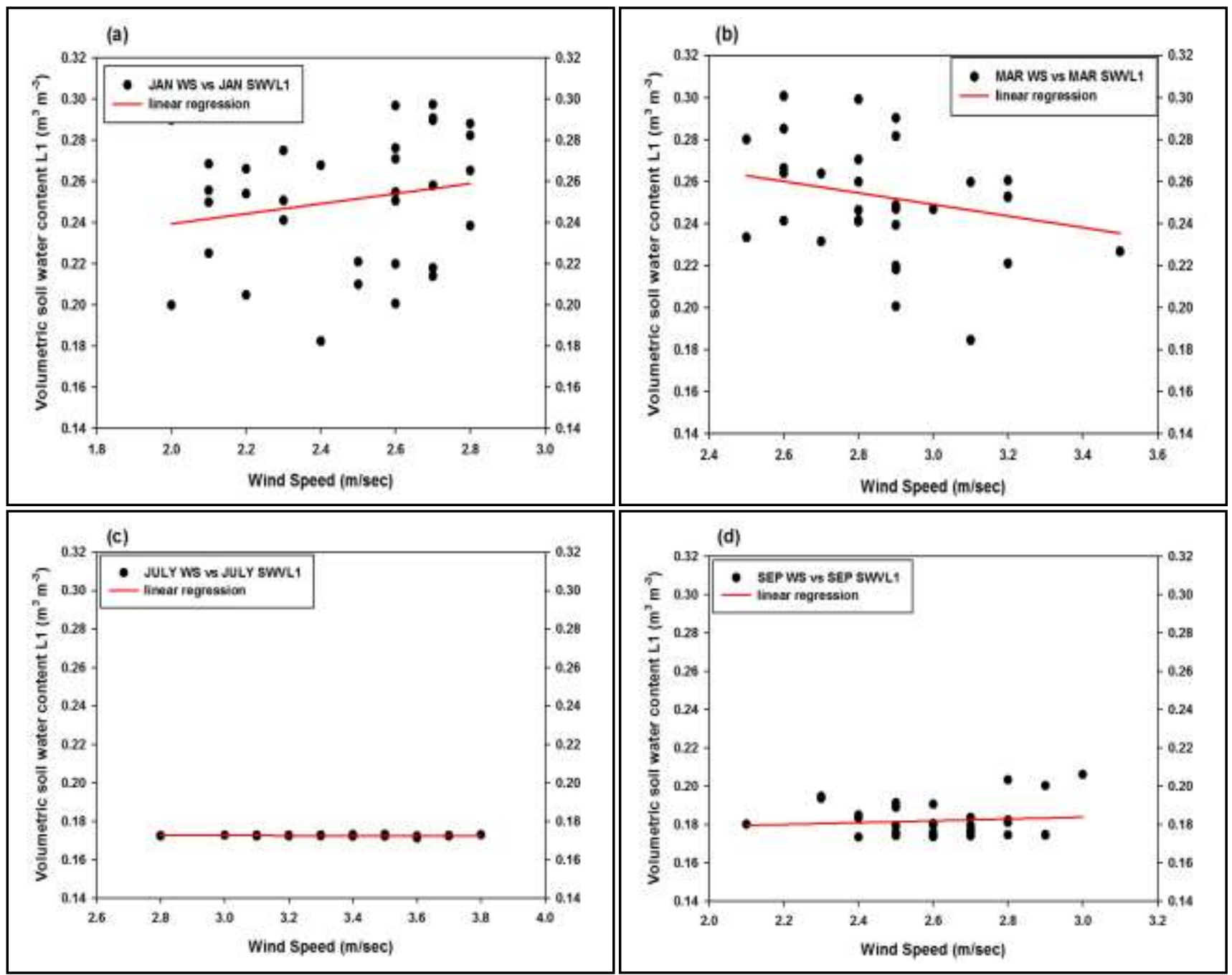

Figure 16. The relationship between surface wind speed and volumetric soil water content for the first level of the soil of Mosul city from 1979 to 2011 (a) January, (b) March, (c) July and (d) September. 
Proc. of the Second Intl. Conf. on Advances in Bio-Informatics and Environmental Engineering - ICABEE 2015 Copyright (C) Institute of Research Engineers and Doctors, USA .All rights reserved.

ISBN: 978-1-63248-043-9 doi: 10.15224/ 978-1-63248-043-9-107
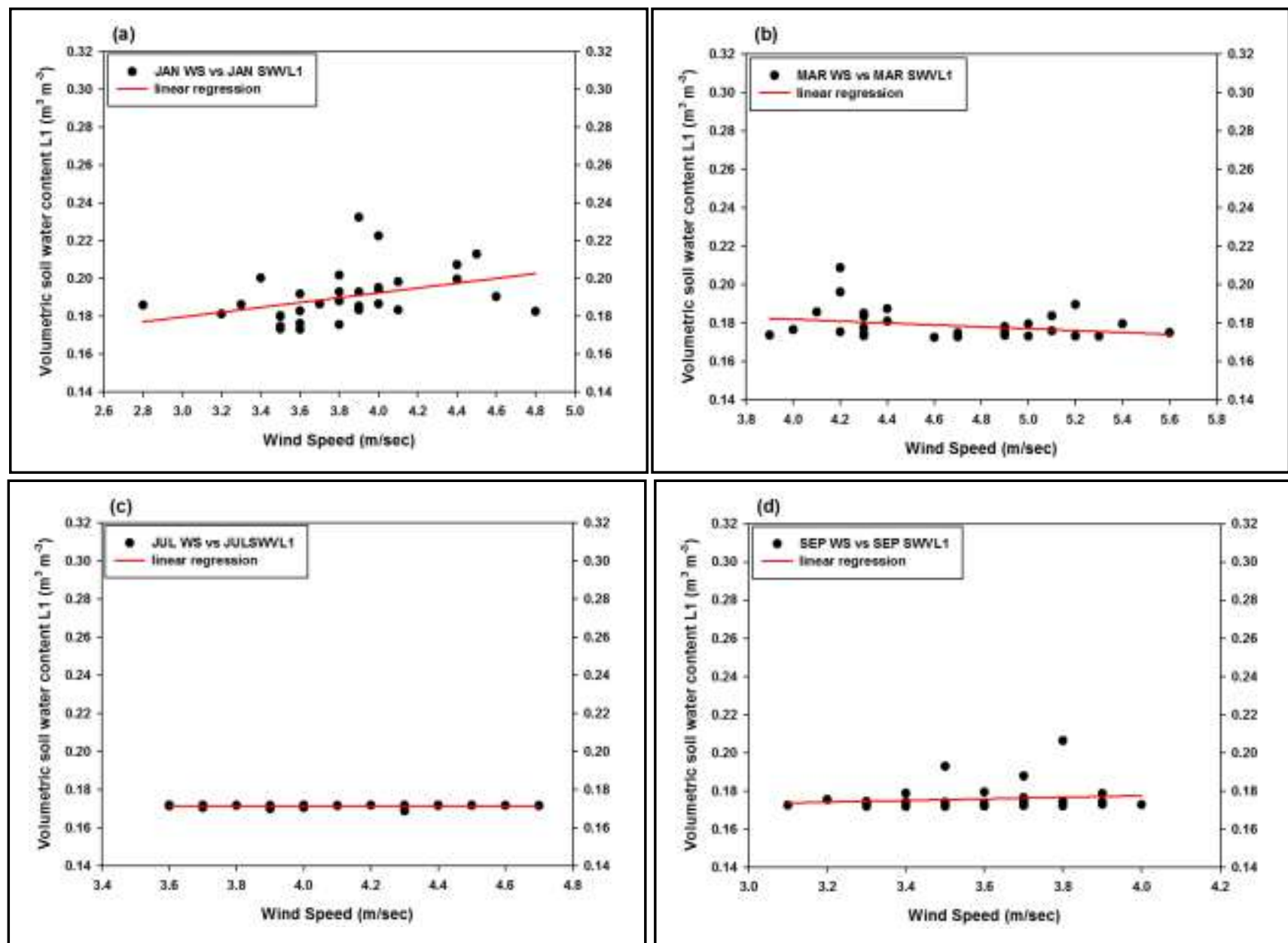

Figure 17. The relationship between surface wind speed and volumetric soil water content for the first level of the soil of Rutba city from 1979 to 2011 (a) January, (b) March, (c) July and (d) September.

TABLE 5. Results of tests (Mann-Kendall, Spearman Rho) and simple linear regression to test the strength of the relationship between surface wind speed and volumetric soil water content at the first level of the soil at depth (0.0 - 0.07 meter), months (January, March, July and September) areas (Baghdad, Basra, Mosul and Rutba).

\begin{tabular}{|c|c|c|c|c|c|c|c|c|}
\hline \multirow{2}{*}{ Months } & \multirow{2}{*}{ Areas } & \multicolumn{2}{|c|}{ Mann-Kendall Test } & \multicolumn{2}{|c|}{ Spearman Rho Test } & \multicolumn{3}{|c|}{ Simple Linear Regression } \\
\hline & & $\tau$ & Correlation & $\mathbf{r}_{\mathrm{s}}$ & Correlation & Slope & P-Value & Relationship \\
\hline \multirow{4}{*}{ January } & Baghdad & -0.1 & Reverse slightly & -0.1 & Reverse slightly & -0.007 & 0.6 & No linear \\
\hline & Basra & -0.3 & Reverse few & -0.4 & Reverse medium & -0.03 & 0.02 & Linear \\
\hline & Mosul & 0.2 & Extrusive few & 0.3 & Extrusive few & 0.02 & 0.3 & No linear \\
\hline & Rutba & 0.4 & Extrusive medium & 0.5 & Extrusive medium & 0.01 & 0.03 & Linear \\
\hline \multirow{4}{*}{ March } & Baghdad & -0.2 & Reverse few & -0.3 & Reverse few & -0.02 & 0.05 & Linear \\
\hline & Basra & -0.2 & Reverse few & -0.3 & Reverse few & -0.009 & 0.2 & No linear \\
\hline & Mosul & -0.2 & Reverse few & -0.2 & Reverse few & -0.03 & 0.2 & No linear \\
\hline & Rutba & -0.1 & Reverse slightly & -0.2 & Reverse few & -0.005 & 0.1 & No linear \\
\hline \multirow{4}{*}{ July } & Baghdad & -0.2 & Reverse few & -0.3 & Reverse few & -0.00004 & 0.9 & No linear \\
\hline & Basra & $\begin{array}{l}-0.1 \\
\end{array}$ & Reverse slightly & -0.2 & Reverse few & -0.0007 & 0.5 & No linear \\
\hline & Mosul & 0.03 & No correlation & 0.002 & No correlation & -0.00005 & 0.9 & No linear \\
\hline & Rutba & 0.06 & No correlation & 0.09 & No correlation & 0.00008 & 0.9 & No linear \\
\hline \multirow{4}{*}{ September } & Baghdad & -0.1 & Reverse slightly & -0.1 & Reverse slightly & -0.0001 & 0.7 & No linear \\
\hline & Basra & 0 & No correlation & -0.02 & No correlation & -0.0001 & 0.9 & No linear \\
\hline & Mosul & -0.01 & No correlation & -0.01 & No correlation & 0.005 & 0.6 & No linear \\
\hline & Rutba & 0.05 & No correlation & 0.07 & No correlation & 0.004 & 0.5 & No linear \\
\hline
\end{tabular}




\section{Conclusions}

- Volumetric soil water content at the first level of the soil in the event of an increase in all study areas during the 33 months of the year January, July and September except Mosul, in the case of a decrease in the month of January. In the month of March in the case of a decrease for all study areas.

- Greatest value of volumetric soil water content recorded in Mosul, and the lowest value in Basra.

- The relationship between the volumetric soil water content at the first level of the soil and the relative humidity in the study areas indicated the presence of a positive correlation medium relationship to a high of months January and March, there is no linear relationship in the months July and September.

- The relationship between the volumetric soil water content at the first level of the soil and surface wind speed in the study areas indicated the presence of a few inverse correlation to the medium when months January and March in Baghdad and Basra, and there is no linear relationship in the months July and September. The Mosul and Rutba was a positive relationship medium in the month of January and there is no linear relationship in the months March, July and September.

\section{References}

[1] Walker J. ,"Estimating Soil Moisture Profile Dynamics from NearSurface Soil Moisture Measurements and Standard Meteorological Data", Ph.D. dissertation, The University of Newcastle, Australia, 1999.

[2] Lingli W. and John J. Q. ,"Satellite remote sensing applications for surface soil moisture monitoring: A review ", Journal of Front. Earth Sci. China, Vol.3 issue 2, pp. 237-247, 2009.

[3] Commission of Agricultural Meteorology (CAGM),"Report of the RA II Working Group on Agricultural Meteorology", Part IV: Drought and Desertification. Report No. 52", WMO/TD-No. 524, pp. 1-43, 1993.

[4] Fast, J. D. and Mc Corcle, M. D. ,"The Effect of Heterogeneous Soil Moisture on a Summer Baroclinic Circulation in the Central United States", Journal of Mon. Wearer., Vol.119, pp. 2140-2167, 1991.

[5] Nancy M. T., Keith S. Porter and Robert J. W. ,"Water and the Soil", Dept. of Agronomy Cornell University, 2012.

[6] Paetzold, R. F., Gish, T. J. and Jackson, T. J., ,NMR measurements of soil water content", Proceedings of the International Conference on the Measurement of Soil and Plant Water Status, Logan, Utah, Vol. 1, pp. 255-260, 1978.

[7] Dr. James E. Arnold ,"Soil moisture", 1999. http://www.ghcc.msfc.nasa.gov/landprocess/lp_home.html

[8] Burt T. P., Chorley R. J., Brunsden D., Cox N. J. and Goudie A. S. ,"Quaternary and Recent Processes and Forms. Landforms or the Development of Geomorphology", Geological Society. pp. 129-164, 2008.

[9] Marthaler, H. P., eta. ,"A pressure transducer for field tensiometers", Soil Science Society of America Journal, vol. 47, pp. 624-627, 1983.

[10] Qing Xu,"Effects of rainfall on soil moisture and water movement in a subalpine dark coniferous forest in southwestern China", Hydrological Processes, Published online in Wiley Online Library, 2011.
[11] Osama T. Al-Taai, Mohammed M. Ahmed and Thaer K. Jawad ,"Influence of Rainfall on Soil Water Content in Iraq", International Journal of Agriculture Innovations and Research Vol. 3, No. 2, pp. 618-627, 2014.

[12] Thaer K. Jawad and Osama T. Al-Taai ,"Effect of Temperature on Soil Water Content in Baghdad City", Al-Mustansiriyah J. of Science, Vol. 24, No. 6, pp. 95-104, 2013.

[13] Gatley, D. P. ,"Psychometric chart celebrates 100th anniversary", ASHRAE Journal 46 Vol.11, pp. 16 - 20, 2004.

[14] Lawrence, Mark G. ,'The Relationship between Relative Humidity and the Dew point Temperature in Moist Air", A Simple Conversion and Applications. Bull. Amer. Meteor. Soc., Vol.86, pp. 225-233, 2005.

[15] Jet Stream ,"Origin of Wind", National Weather Service Southern Region Headquarters, Retrieved, 2009.

[16] Makarieva, Anastassia V. G., Gorshkov, and D. Sheil A. D. ,"Where do winds come from? A new theory on how water vapor condensation influences atmospheric pressure and dynamics", Atmospheric Chemistry and Physics, issue 13 Vol.2, pp.1039-1056, 2013.

[17] Phil K. ,"Cause of Wind", 2004. http://www.newton.dep.anl.gov/askasci/wea00/wea00187.htm

[18] Gardner, W. H. and Calissendorff, C. ,"Gamma ray and neutron attenuation measurements of soil bulk density and soil water content Proceedings of the Symposium on Techniques in Soil Physics and Irrigation Studies", Istanbul. International Atomic Energy Agency, Vienna, pp. 101-113, 1967.

[19] Noborio K. ,"Measurement of soil water content and electrical conductivity by time domain reflect meter: A review", Computers and Electronics in Agriculture, Vol.31, pp.213-237, 2001.

[20] Uppala eta ,"The ERA-40 re-analysis", Q. J. R. Meteorology Soc., Vol. 131, pp. 2961-3012, 2005.

[21] D. P. Dee,"The ERA-Interim reanalysis: configuration and performance of the data assimilation system", Q. J. R. meteorology Soc., Vol.137, pp. 553-597, 2011.

[22] J. K. Gibson, P. Kållberg, S. Uppala, A. Hernandez, A. Nomura, and E. Serrano ,"ERA-15 Description", ECMWF Re-Analysis Project Report Series, European Centre for Medium-Range Weather Forecasts, 1999.

[23] Discretization of soil layers ,"Soil depths", 2012. http://www.ecmwf.int/products/data/technical/soil/discret_soil_lay .html

[24] Buringh, P. ,"Soils and soil conditions in Iraq", Ministry of Agriculture, Baghdad, Iraq, 1960.

[25] The European Centre for Medium-Range Weather Forecasts Reanalysis at ECMWF, 2013. http://www.ecmwf.int/research/era/do/get/Reanalysis_ECMWF

[26] Tara Mohamed Anwar Omer," Iraq Country Profile", University of Sulaimaniyah, Iraq, 2011.

[27] Yazdani Mohammad Reza, Khoshhal Dastjerdi Javad, Mahdavi Mohammad and Sharma Ashish ,"Trend Detection of the Rainfall and Air Temperature Data in the Zayandehrud Basin.", Journal of Applied Sciences, Vol.11, pp. 2125-2134, 2011.

[28] Mohamed Sameh ,"Data analysis management and industrial engineering", 2009.

http://samehar.wordpress.com/2009/08/13/0120809/

[29] Kendall's Tau-b Correlation Coefficient, 2011.

http://www.support.sas.com/documentation/cdl/en/procstat/63104 /HTML /default/viewer.htm\#procstat_corr_sect015.htm.

[30] Mathematics in Education and Industry (MEI) ,"Spearman's rank correlation", 2007.

http://www.mei.org.uk./

[31] Williams, F. ,"Reasoning with statistics. How to read quantitative," research $4^{\text {th }}$ ed. Fort Worth. Harcourt Brace Jovanovich College Publishers, 1992. 
Proc. of the Second Intl. Conf. on Advances in Bio-Informatics and Environmental Engineering - ICABEE 2015 Copyright (C) Institute of Research Engineers and Doctors, USA .All rights reserved.

ISBN: 978-1-63248-043-9 doi: 10.15224/ 978-1-63248-043-9-107

[1] About Author: Dr. Osama T. Al-Taai

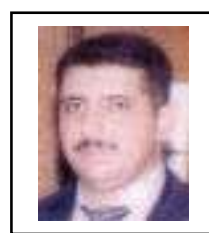

[Is Ph.D. in Atmospheric Sciences (with specialization in Fuzzy logic) from AlMustansiriyah University, Iraq in 2007. He has completed M.Sc. Atmospheric Sciences from AlMustansiriyah University, Iraq in 2001, He has been teaching and conducting research in Atmospheric Sciences and related fields in the College of Science, Al Mustansiriyah University Since 2001. He has published more than 10 research papers, Dr. Al-Taai supervised more than 3 M.Sc. Thesis. $\mathrm{He}$ is currently working as Assistant Professor in the Department of Atmospheric Sciences, College of Science, AlMustansiriyah University, Baghdad - Iraq]

[2] About Author: Thaer K. Jawad

\begin{tabular}{l|l|} 
[I got an undergraduate degree in 2007, Master's \\
degree in the Atmospheric Sciences in 2014 and was \\
a research project is The Influence of Some \\
Meteorological Parameters on Soil Water Content in \\
Iraq]
\end{tabular}

